TITLE:

\title{
BIOASSAY DATA FOR MARINE POLLUTION USING SEA URCHIN EGGS, 1972 AND 1973
}

AUTHOR(S):

Kobayashi, Naomasa

\section{CITATION:}

Kobayashi, Naomasa. BIOASSAY DATA FOR MARINE POLLUTION USING SEA URCHIN EGGS, 1972 AND 1973. PUBLICATIONS OF THE SETO MARINE BIOLOGICAL LABORATORY 1974, 21(5-6): 411-439

ISSUE DATE:

1974-12-23

URL:

http://hdl.handle.net/2433/175871

RIGHT: 


\section{BIOASSAY DATA FOR MARINE POLLUTION USING SEA URCHIN EGGS, 1972 AND 1973}

\section{2}

Ten experiments for biological assay were made using sea urchin eggs to check marine pollution around the Seto Marine Biological Laboratory.

I. Winter season, January 16. Eggs of Hemicentrotus pulcherrimus (A. Agassiz) were used, see Table 1 .

II. Spring season, three experiments were made in March-May using Hemicentrotus pulcherrimus or Anthocidaris crassispina (A. Agassiz) eggs.

1. March 2, see Table 2 .

2. April 1, see Table 3.

3. May 14, see Table 4.

III. Summer season, four experiments were made in June-August, using Anthocidaris crassispina eggs.

1. June 11 , see Table 5 .

2. July 11 , see Table 6 .

3. August 7 , see Table 7 .

4. August 24 , see Table 8 .

IV. Autumn season, two experiments were made in September-November, using Anthocidaris crassispina or Pseudocentrotus depressus (A. Agassiz) eggs.
1. September 23, see Table 9.
2. November 23. see Table 10.

(Notes common to all tables : Fertilization membrane formation examined $3 \mathrm{~min}$. after insemination; minutes and hours in parentheses respectively after First cleavage and Gastrulation indicate the time after insemination; the maturation state of gonads used was nearly ripe to full ripe; Degree of inhibitory effect 1 shows the non-inhibitory and ordinary state and 2 the weakly inhibitory state of the sea water (see Kobayashi 1972).)

The COD values were measured by Dr. Sh. Fuse.

\section{3}

Seven experiments were made as follows.

I. Winter season, February 21, Eggs of Hemicentrotus pulcherrimus were used, see Table 11.

II. Spring season, two experiments were made in March-May, using Hemicentrotus pulcherrimus or Anthocidaris crassispina eggs.

1. March 20, see Table 12.

2. May 4, see Table 13.

III. Summer season, two experiments were made in July-August, using Anthocidaris crassispina eggs.

1. July 3 , see Table $14 . \quad 2$. August 30 , see Table 15.

IV. Autumn season, two experiments were made in September-November, using "Anthocidaris crassispina or Pseudocentrotus depressus eggs.

1. September 14, see Table $16 . \quad 2$. November 27, see Table 17.

(Notes common to all tables: See the notes mentioned above, besides the following ones; For the $0 \mathrm{hr}$. old eggs, Degree of inhibitory effect 1 shows the non-inhibitory and ordinary state and 2 the weakly inhibitory state of the sea water (see Publ. Seto Mar. Biol. Lab., Vol. XIX, No. 6, p. 378, Table 2, 1972. For the 3-10 hrs. old eggs, Degree of inhibitory effect 0 shows the noninhibition state, 1 the slight inhibition, 2 the weak inhibition and 3 the moderate inhibition state of the sea water (see Publ. Seto Mar. Biol. Lab., Vol. XXI, No. 5/6, p. 391 Table 8, 1974).

The COD values were measured by Dr. Sh. Fuse.

NAOMASA KOBAYASHI

Publ. Seto Mar. Biol. Lab., XXI, 411-432, 1974. (Biological data 2) 
Table 1. Results of the Jan. 16 experiment with eggs of Hemicentrotus pulcherrimus.

Wind: NW 2. Test water temperature : $17^{\circ} \mathrm{C}$. (warmed).

\begin{tabular}{|c|c|c|c|c|c|c|c|c|c|c|}
\hline \multirow{2}{*}{ Location } & \multirow{2}{*}{ 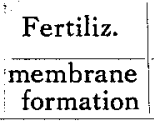 } & \multicolumn{3}{|c|}{ First cleavage (90 min.) } & \multicolumn{3}{|c|}{ Gastrulation (24 hrs.) } & \multicolumn{2}{|c|}{ Other notes } & \multirow{2}{*}{$\begin{array}{l}\text { Dagree of } \\
\text { inhibitory } \\
\text { effect }\end{array}$} \\
\hline & & 1 cell & $\begin{array}{c}2 \text { cell } \\
(\text { normal })\end{array}$ & $\begin{array}{c}\text { multi-cell } \\
\text { (polysperm) }\end{array}$ & $\begin{array}{c}\text { permanent } \\
\text { blastula }\end{array}$ & $\begin{array}{c}\text { gastrula } \\
\text { (normal) }\end{array}$ & exogastrula & $\begin{array}{c}\text { abnormal } \\
\text { develop. }\end{array}$ & COD & \\
\hline $\begin{array}{l}\text { Running } \\
\text { sea water of } \\
\text { Laboratory }\end{array}$ & $\begin{array}{l}99.6 \% \\
99.2 \\
99.7\end{array}$ & $\begin{array}{l}0.8 \% \\
1.0 \\
0.7\end{array}$ & $\begin{array}{l}99.2 \% \\
99.0 \\
99.3\end{array}$ & $\begin{array}{l}0 \% \\
0 \\
0 \\
\end{array}$ & $\begin{array}{l}0.5 \% \\
0.3 \\
0.2\end{array}$ & $\begin{array}{l}99.5 \% \\
99.7 \\
99.8 \\
\end{array}$ & $\begin{array}{l}0 \% \\
0 \\
0 \\
\end{array}$ & & ppm & 1 \\
\hline $\begin{array}{l}\text { Water from open sea } \\
\text { side of Hatakejima } \\
\text { Surface }\end{array}$ & $\begin{array}{l}99.5 \\
99.4 \\
99.5\end{array}$ & $\begin{array}{l}0.9 \\
0.7 \\
1.0\end{array}$ & $\begin{array}{l}99.1 \\
99.2 \\
99.0\end{array}$ & $\begin{array}{l}0 \\
0.1 \\
0\end{array}$ & $\begin{array}{l}0.3 \\
0.2 \\
0.2\end{array}$ & $\begin{array}{l}99.7 \\
99.8 \\
99.7\end{array}$ & $\begin{array}{l}0 \\
0 \\
0,1\end{array}$ & & & 1 \\
\hline $\begin{array}{l}\text { Water from land } \\
\text { side of Hatakejima } \\
\text { Surface }\end{array}$ & $\begin{array}{l}99.4 \\
99.3 \\
99.6 \\
\end{array}$ & $\begin{array}{l}1.0 \\
1.1 \\
0.5\end{array}$ & $\begin{array}{l}99.0 \\
98.9 \\
99.4 \\
\end{array}$ & $\begin{array}{l}0 \\
0 \\
0.1\end{array}$ & $\begin{array}{l}0.2 \\
0.7 \\
0.6\end{array}$ & $\begin{array}{l}99.8 \\
99.3 \\
99.4 \\
\end{array}$ & $\begin{array}{l}0 \\
0 \\
0 \\
\end{array}$ & & & 1 \\
\hline $\begin{array}{l}\text { Sea water from } \\
\text { Tsunashirazu cove } \\
\text { Surface }\end{array}$ & $\begin{array}{l}99.3 \\
99.4 \\
99.2\end{array}$ & $\begin{array}{l}0.9 \\
1.0 \\
1.0\end{array}$ & $\begin{array}{l}99.1 \\
99.0 \\
98.9\end{array}$ & $\begin{array}{l}0 \\
0 \\
0.1\end{array}$ & $\begin{array}{l}0.3 \\
0.6 \\
0.7\end{array}$ & $\begin{array}{l}99.6 \\
99.4 \\
99.2\end{array}$ & $\begin{array}{l}0.1 \\
0 \\
0.1\end{array}$ & & & 1 \\
\hline
\end{tabular}

Table 2. Results of the Mar. 2 experiment with eggs of Hemicentrotus pulcherrimus.

Wind: NW 1. Test water temperature: $18^{\circ} \mathrm{C}$. (warmed).

\begin{tabular}{|c|c|c|c|c|c|c|c|c|c|c|}
\hline \multirow{2}{*}{ Location } & \multirow{2}{*}{$\begin{array}{c}\text { Fertiliz. } \\
\text { membrane } \\
\text { formation }\end{array}$} & \multicolumn{3}{|c|}{ First cleavage $(90 \mathrm{~min})}$. & \multicolumn{3}{|c|}{ Gastrulation ( 24 hrs.) } & \multicolumn{2}{|c|}{ Other notes } & \multirow{2}{*}{$\begin{array}{l}\text { Degree of } \\
\text { inhibitory } \\
\text { effect }\end{array}$} \\
\hline & & 1 cell & $\begin{array}{c}2 \text { cell } \\
(\text { normal) }\end{array}$ & $\left(\begin{array}{c}\text { multi-cell } \\
\text { (polysperm) }\end{array}\right.$ & $\begin{array}{c}\text { permanent } \\
\text { blastula }\end{array}$ & $\begin{array}{c}\text { gastrula } \\
\text { (normal) }\end{array}$ & exogastrula & $\begin{array}{l}\text { abnormal } \\
\text { develop. }\end{array}$ & COD & \\
\hline $\begin{array}{l}\text { Running } \\
\text { sea water of } \\
\text { Laboratory }\end{array}$ & $\begin{array}{l}99.8 \% \\
98.3 \\
99.1\end{array}$ & $\begin{array}{l}0.8 \% \\
2.1 \\
0.7\end{array}$ & $\begin{array}{l}99.2 \% \\
97.7 \\
99.2\end{array}$ & $\begin{array}{l}0.9 \\
0.2^{9} \\
0.1\end{array}$ & $\begin{array}{l}0.2 \% \\
0.2 \\
0.1\end{array}$ & $\begin{array}{l}99.8 \% \\
99.8 \\
99.9\end{array}$ & $\begin{array}{l}0 \\
0 \\
0\end{array}$ & & $\mathrm{ppm}$ & 1 \\
\hline $\begin{array}{l}\text { Water from open sea } \\
\text { side of Hatakejima } \\
\text { Surface }\end{array}$ & $\begin{array}{l}99.7 \\
98.2 \\
99.2\end{array}$ & $\begin{array}{l}0.7 \\
2.2 \\
0.5\end{array}$ & $\begin{array}{l}99.3 \\
97.4 \\
99.3\end{array}$ & $\begin{array}{l}0 \\
0.4 \\
0.2\end{array}$ & $\begin{array}{l}0.1 \\
0.2 \\
0.2\end{array}$ & $\begin{array}{l}99.9 \\
99.7 \\
99.8\end{array}$ & $\begin{array}{l}0 \\
0.1 \\
0\end{array}$ & & & 1 \\
\hline $\begin{array}{l}\text { Water from land } \\
\text { side of Hatakejima } \\
\text { Surface }\end{array}$ & $\begin{array}{l}99.3 \\
98.1 \\
99.0\end{array}$ & $\begin{array}{l}1.3 \\
2.5 \\
1.8\end{array}$ & $\begin{array}{l}98.5 \\
97.2 \\
97.9\end{array}$ & $\begin{array}{l}0.2 \\
0.3 \\
0.3\end{array}$ & $\begin{array}{l}0.2 \\
0.4 \\
0.3\end{array}$ & $\begin{array}{l}99.8 \\
99.5 \\
99.6\end{array}$ & $\begin{array}{l}0 \\
0.1 \\
0.1\end{array}$ & & & 1 \\
\hline $\begin{array}{l}\text { Sea water from } \\
\text { Tsunashirazu cove } \\
\text { Surface }\end{array}$ & $\begin{array}{l}98.7 \\
97.2 \\
98.7 \\
\end{array}$ & $\begin{array}{l}1.9 \\
2.9 \\
2.3\end{array}$ & $\begin{array}{l}97.7 \\
96.7 \\
97.4 \\
\end{array}$ & $\begin{array}{l}0.4 \\
0.4 \\
0.3 \\
\end{array}$ & $\begin{array}{l}0.3 \\
0.4 \\
0.3 \\
\end{array}$ & $\begin{array}{l}99.6 \\
99.6 \\
99.7\end{array}$ & $\begin{array}{l}0.1 \\
0 \\
0\end{array}$ & & & 1 \\
\hline
\end{tabular}


Table 3. Results of the Apr. 1 experiment with eggs of Hemicentrotus pulcherrimus.

Wind. NW 2. Test water temperature: $18^{\circ} \mathrm{C}$. (warmed).

\begin{tabular}{|c|c|c|c|c|c|c|c|c|c|c|}
\hline \multirow{2}{*}{ Location } & \multirow{2}{*}{$\begin{array}{c}\text { Fertiliz. } \\
\text { membrane } \\
\text { formation }\end{array}$} & \multicolumn{3}{|c|}{ First cleavage ( 90 min.) } & \multicolumn{3}{|c|}{ Gastrulation ( $24 \mathrm{hrs}$.) } & \multicolumn{2}{|c|}{ Other notes } & \multirow{2}{*}{$\begin{array}{l}\text { Degree of } \\
\text { inhibitory } \\
\text { effect }\end{array}$} \\
\hline & & 1 cell & $\begin{array}{c}2 \text { cell } \\
\text { (normal) }\end{array}$ & $\begin{array}{c}\text { multi-cell } \\
\text { (polysperm) }\end{array}$ & $\begin{array}{c}\text { permanent } \\
\text { blastula }\end{array}$ & $\begin{array}{c}\text { gastrula } \\
\text { (normal) }\end{array}$ & exogastrula & $\begin{array}{c}\text { abnormal } \\
\text { develop. }\end{array}$ & $\mathrm{COD}$ & \\
\hline $\begin{array}{l}\text { Running } \\
\text { sea water of } \\
\text { Laboratory }\end{array}$ & $\begin{array}{l}97.8 \% \\
98.3 \\
96.8\end{array}$ & $\begin{array}{l}3.2 \% \\
2.2 \\
4.7 \\
\end{array}$ & $\begin{array}{l}96.8 \% \\
97.8 \\
95.3 \\
\end{array}$ & $\begin{array}{ll}0 & \not 6 \\
0 & \\
0 & \\
\end{array}$ & $\begin{array}{l}3.2 \% \\
0.7 \\
2.9 \\
\end{array}$ & $\begin{array}{l}96.7 \% \\
99.3 \\
97.0\end{array}$ & $\begin{array}{l}0.1 \% \\
0 \\
0.1\end{array}$ & & ppm & 1 \\
\hline $\begin{array}{l}\text { Water from open sea } \\
\text { side of Hatakejima } \\
\text { Surface }\end{array}$ & $\begin{array}{l}87.9 \\
90.2 \\
89.3\end{array}$ & $\begin{array}{l}12.7 \\
10.2 \\
12.8\end{array}$ & $\begin{array}{l}87.3 \\
89.4 \\
87.2\end{array}$ & $\begin{array}{l}0 \\
0.4 \\
0\end{array}$ & $\begin{array}{l}4.3 \\
0.9 \\
3.1\end{array}$ & $\begin{array}{l}95.5 \\
99.1 \\
96.7 \\
\end{array}$ & $\begin{array}{l}0.2 \\
0 \\
0.2 \\
\end{array}$ & & & 1 \\
\hline $\begin{array}{l}\text { Water from land } \\
\text { side of Hatakejima } \\
\text { Surface }\end{array}$ & $\begin{array}{l}97.1 \\
97.3 \\
95.2\end{array}$ & $\begin{array}{l}4.2 \\
4.6 \\
5.7\end{array}$ & $\begin{array}{l}95.8 \\
93.4 \\
94.3\end{array}$ & $\begin{array}{l}0 \\
0 \\
0\end{array}$ & $\begin{array}{l}3.3 \\
0.9 \\
3.2 \\
\end{array}$ & $\begin{array}{l}96.5 \\
99.0 \\
96.6 \\
\end{array}$ & $\begin{array}{l}0.2 \\
0.1 \\
0.2\end{array}$ & & & 1 \\
\hline $\begin{array}{l}\text { Sea water from } \\
\text { Tsunashirazu cove } \\
\text { Surface }\end{array}$ & $\begin{array}{l}84.2 \\
85.3 \\
83.3\end{array}$ & $\begin{array}{l}16.4 \\
14.8 \\
17.5\end{array}$ & $\begin{array}{l}83.6 \\
84.9 \\
82.5\end{array}$ & $\begin{array}{l}0 \\
0.3 \\
0\end{array}$ & $\begin{array}{l}4.7 \\
1.1 \\
3.2\end{array}$ & $\begin{array}{l}95.0 \\
98.8 \\
96.5\end{array}$ & $\begin{array}{l}0.3 \\
0.1 \\
0.3\end{array}$ & & & 1 \\
\hline
\end{tabular}

Table 4. Results of the May 14 experiment with eggs of Anthocidaris crassispina.

Wind : 0 . Test water temperature: $20^{\circ} \mathrm{C}$.

\begin{tabular}{|c|c|c|c|c|c|c|c|c|c|c|}
\hline \multirow{2}{*}{ Location } & \multirow{2}{*}{$\mid \begin{array}{c}\text { Fertiliz. } \\
\begin{array}{c}\text { membrane } \\
\text { formation }\end{array} \mid\end{array}$} & \multicolumn{3}{|c|}{ First cleavage $(75 \mathrm{~min})}$. & \multicolumn{3}{|c|}{ Gastrulation ( $24 \mathrm{hrs}$ ) } & \multicolumn{2}{|c|}{ Other notes } & \multirow{2}{*}{$\begin{array}{l}\text { Degree of } \\
\text { inhibitory } \\
\text { effect }\end{array}$} \\
\hline & & 1 cell & $\begin{array}{c}2 \text { cell } \\
\text { (normal) }\end{array}$ & $\begin{array}{c}\text { multi-cell } \\
\text { (polysperm) }\end{array}$ & $\begin{array}{c}\text { permanent } \\
\text { blastula }\end{array}$ & $\begin{array}{c}\text { gastrula } \\
\text { (normal) }\end{array}$ & exogastrula & $\begin{array}{c}\text { abnormal } \\
\text { develop. }\end{array}$ & $\mathrm{COD}$ & \\
\hline $\begin{array}{l}\text { Running } \\
\text { sea water of } \\
\text { Laboratory }\end{array}$ & $\begin{array}{l}98.1 \% \\
99.2 \\
98.3\end{array}$ & $\begin{array}{l}2.7 \% \\
1.7 \\
1.2 \\
\end{array}$ & $\begin{array}{l}97.3 \% \\
98.3 \\
98.1\end{array}$ & $\begin{array}{l}0 \quad \% \\
0 \\
0.7\end{array}$ & $\begin{array}{l}7.3 \% \\
0.7 \\
0.6\end{array}$ & $\begin{array}{l}92.4 \% \\
99.3 \\
99.4\end{array}$ & $\begin{array}{l}0.3 \% \\
0 \\
0 \\
\end{array}$ & & $\begin{array}{l}\text { ppm } \\
1.96\end{array}$ & 1 \\
\hline $\begin{array}{l}\text { Water from open sea } \\
\text { side of Hatakejima } \\
\text { Surface }\end{array}$ & $\begin{array}{l}97.8 \\
98.7 \\
97.6 \\
\end{array}$ & $\begin{array}{l}3.0 \\
1.6 \\
1.6 \\
\end{array}$ & $\begin{array}{l}97.0 \\
98.4 \\
97.2 \\
\end{array}$ & $\begin{array}{l}0 \\
0 \\
1.2 \\
\end{array}$ & $\begin{array}{l}7.3 \\
1.0 \\
0.8 \\
\end{array}$ & $\begin{array}{l}92.6 \\
99.0 \\
99.2\end{array}$ & $\begin{array}{l}0.1 \\
0 \\
0\end{array}$ & & 2.20 & 1 \\
\hline $\begin{array}{l}\text { Water from land } \\
\text { side of Hatakejima } \\
\text { Surface }\end{array}$ & $\begin{array}{l}94.3 \\
96.3 \\
97.1 \\
\end{array}$ & $\begin{array}{l}5.6 \\
2.7 \\
1.7 \\
\end{array}$ & $\begin{array}{l}92.3 \\
95.7 \\
96.8 \\
\end{array}$ & $\begin{array}{l}2.1 \\
1.6 \\
1.5\end{array}$ & $\begin{array}{l}7.8 \\
2.8 \\
0.2\end{array}$ & $\begin{array}{l}91.8 \\
97.1 \\
99.0\end{array}$ & $\begin{array}{l}0.4 \\
0.1 \\
0\end{array}$ & & 3.12 & 1 \\
\hline $\begin{array}{l}\text { Sea water from } \\
\text { Tsunashirazu cove } \\
\text { Surface }\end{array}$ & $\begin{array}{l}91.3 \\
92.3 \\
95.1\end{array}$ & $\begin{array}{l}6.7 \\
4.6 \\
5.0\end{array}$ & $\begin{array}{l}90.1 \\
93.1 \\
92.3\end{array}$ & $\begin{array}{l}3.2 \\
2.3 \\
2.7\end{array}$ & $\begin{array}{l}8.3 \\
3.3 \\
2.7\end{array}$ & $\begin{array}{l}91.2 \\
96.5 \\
97.3 \\
\end{array}$ & $\begin{array}{l}0.5 \\
0.2 \\
0\end{array}$ & & 2.90 & 1 \\
\hline
\end{tabular}


Table 5. Results of the June 11 experiment with eggs of Anthocidar is crassispina. Wind: 0 . Test water temperature : $23^{\circ} \mathrm{C}$

\begin{tabular}{|c|c|c|c|c|c|c|c|c|c|c|}
\hline \multirow{2}{*}{ Location } & \multirow{2}{*}{$\mid \begin{array}{c}\text { Fertiliz. } \\
\text { membrane } \\
\text { formation }\end{array}$} & \multicolumn{3}{|c|}{ First cleavage ( $75 \mathrm{~min})}$. & \multicolumn{3}{|c|}{ Gastrulation (20 hrs.) } & \multicolumn{2}{|c|}{ Other notes } & \multirow{2}{*}{$\begin{array}{l}\text { Degree of } \\
\text { inhibitory } \\
\text { effect }\end{array}$} \\
\hline & & 1 cell & $\begin{array}{c}2 \text { cell } \\
\text { (normal) }\end{array}$ & $\left|\begin{array}{c}\text { multi-cell } \\
\text { (polysperm) }\end{array}\right|$ & $\begin{array}{c}\text { permanent } \\
\text { blastula }\end{array}$ & $\begin{array}{c}\text { gastrula } \\
\text { (normal) }\end{array}$ & exogastrula & $\begin{array}{l}\text { abnormal } \\
\text { develop. }\end{array}$ & COD & \\
\hline $\begin{array}{l}\text { Running } \\
\text { sea water of } \\
\text { Laboratory }\end{array}$ & $\begin{array}{l}99.49 \\
98.7 \\
99.2\end{array}$ & $\begin{array}{l}0.6 \% \\
1.4 \\
0.9\end{array}$ & $\begin{array}{l}99.3 \% \\
98.5 \\
99.0\end{array}$ & $\begin{array}{l}0.1 \% \\
0.1 \\
0.1\end{array}$ & $\begin{array}{l}0.6 \% \\
2.3 \\
1.2\end{array}$ & $\begin{array}{l}99.4 \% \\
97.5 \\
98.7\end{array}$ & $\begin{array}{l}0 \\
0.2^{2} \\
0.1\end{array}$ & & $\begin{array}{c}\mathrm{ppm} \\
1.66\end{array}$ & 1 \\
\hline $\begin{array}{l}\text { Water from open sea } \\
\text { side of Hatakejima } \\
\text { Surface }\end{array}$ & $\begin{array}{l}99.5 \\
98.8 \\
99.3\end{array}$ & $\begin{array}{l}0.5 \\
1.3 \\
0.9\end{array}$ & $\begin{array}{l}99.3 \\
98.5 \\
99.1\end{array}$ & $\begin{array}{l}0.2 \\
0.2 \\
0\end{array}$ & $\begin{array}{l}0.7 \\
3.1 \\
1.4\end{array}$ & $\begin{array}{l}99.3 \\
96.6 \\
98.5\end{array}$ & $\begin{array}{l}0 \\
0.3 \\
0.1\end{array}$ & & 1.96 & 1 \\
\hline $\begin{array}{l}\text { Water from land } \\
\text { side of Hatakejima } \\
\text { Surface }\end{array}$ & $\begin{array}{l}99.3 \\
98.5 \\
99.1\end{array}$ & $\begin{array}{l}0.7 \\
1.4 \\
1.1\end{array}$ & $\begin{array}{l}99.1 \\
98.3 \\
98.8 \\
\end{array}$ & $\begin{array}{l}0.2 \\
0.3 \\
0.1 \\
\end{array}$ & $\begin{array}{l}0.9 \\
3.3 \\
2.3 \\
\end{array}$ & $\begin{array}{l}99.1 \\
96.5 \\
97.6 \\
\end{array}$ & $\begin{array}{l}0 \\
0.2 \\
0.1 \\
\end{array}$ & & 1.70 & 1 \\
\hline $\begin{array}{l}\text { Sea water from } \\
\text { Tsunashirazu cove } \\
\text { Surface }\end{array}$ & $\begin{array}{l}98.9 \\
98.1 \\
98.4\end{array}$ & $\begin{array}{l}1.1 \\
2.2 \\
1.9\end{array}$ & $\begin{array}{l}98.7 \\
97.5 \\
97.9\end{array}$ & $\begin{array}{l}0.2 \\
0.3 \\
0.2\end{array}$ & $\begin{array}{l}\text { 1. } 3 \\
\text { 3. } 8 \\
\text { 3. } 4\end{array}$ & $\begin{array}{l}98.7 \\
95.9 \\
96.4\end{array}$ & $\begin{array}{l}0 \\
0.3 \\
0.2 \\
\end{array}$ & & 2.08 & 1 \\
\hline
\end{tabular}

Table 6. Results of the July 11 experiment with eggs of Anthocidaris crassispina.

Wind: S 2. Test water temperature : $26^{\circ} \mathrm{C}$.

\begin{tabular}{|c|c|c|c|c|c|c|c|c|c|c|}
\hline \multirow{2}{*}{ Location } & \multirow{2}{*}{\begin{tabular}{|c|} 
Fertiliz. \\
$\begin{array}{c}\text { membrane } \\
\text { formation }\end{array}$ \\
\end{tabular}} & \multicolumn{3}{|c|}{ First cleavage (60 $\mathrm{min})}$. & \multicolumn{3}{|c|}{ Gastrulation ( $17 \mathrm{hrs}$ ) } & \multicolumn{2}{|c|}{ Other notes } & \multirow{2}{*}{$\begin{array}{l}\text { Degree of } \\
\text { inhibitory } \\
\text { effect }\end{array}$} \\
\hline & & 1 cell & $\begin{array}{c}2 \text { cell } \\
\text { (normal) }\end{array}$ & $\begin{array}{c}\text { multi-cell } \\
\text { (polysperm) }\end{array}$ & $\begin{array}{c}\text { permanent } \\
\text { blastula }\end{array}$ & $\begin{array}{c}\text { gastrula } \\
\text { (normal) }\end{array}$ & exogastrula & $\begin{array}{l}\text { abnormal } \\
\text { develop. }\end{array}$ & $\mathrm{COD}$ & \\
\hline $\begin{array}{l}\text { Running } \\
\text { sea water of } \\
\text { Laboratory }\end{array}$ & $\begin{array}{l}92.5 \% \\
94.5 \\
93.2 \\
\end{array}$ & $\begin{array}{l}7.6 \% \\
5.7 \\
7.0\end{array}$ & $\begin{array}{l}92.4 \% \\
94.3 \\
93.0\end{array}$ & $\begin{array}{ll}0 & \% \\
0 & \\
0 & \end{array}$ & $\begin{array}{l}0.2 \% \\
0.1 \\
0.3\end{array}$ & $\begin{array}{l}99.8 \% \\
99.9 \\
99.7\end{array}$ & \begin{tabular}{ll|}
0 & $\%$ \\
0 & \\
0 & \\
\end{tabular} & & 0.16 & 1 \\
\hline $\begin{array}{l}\text { Water from open sea } \\
\text { side of Hatakejima } \\
\text { Surface }\end{array}$ & $\begin{array}{l}93.4 \\
95.2 \\
93.1\end{array}$ & $\begin{array}{l}6.8 \\
5.0 \\
7.1\end{array}$ & $\begin{array}{l}93.2 \\
95.0 \\
92.8\end{array}$ & $\begin{array}{l}0 \\
0 \\
0.1\end{array}$ & $\begin{array}{l}0.1 \\
0.1 \\
0.2\end{array}$ & $\begin{array}{l}99.9 \\
99.9 \\
99.8\end{array}$ & $\begin{array}{l}0 \\
0 \\
0\end{array}$ & & 0.89 & 1 \\
\hline $\begin{array}{l}\text { Water from land } \\
\text { side of Hatakejima } \\
\text { Surface }\end{array}$ & $\begin{array}{l}92.1 \\
94.1 \\
93.3\end{array}$ & $\begin{array}{l}8.2 \\
6.3 \\
6.9\end{array}$ & $\begin{array}{l}91.8 \\
93.7 \\
93.1\end{array}$ & $\begin{array}{l}0 \\
0 \\
0\end{array}$ & $\begin{array}{l}0.3 \\
0.1 \\
0.4\end{array}$ & $\begin{array}{l}99.7 \\
99.9 \\
99.6\end{array}$ & $\begin{array}{l}0 \\
0 \\
0\end{array}$ & & 1.18 & 1 \\
\hline $\begin{array}{l}\text { Sea water from } \\
\text { Tsunashirazu cove } \\
\text { Surface }\end{array}$ & $\begin{array}{l}91.3 \\
93.8 \\
92.5\end{array}$ & $\begin{array}{l}8.9 \\
6.4 \\
7.5\end{array}$ & $\begin{array}{l}91.0 \\
93.6 \\
92.4\end{array}$ & $\begin{array}{l}0.1 \\
0 \\
0.1\end{array}$ & $\begin{array}{l}0.4 \\
0.2 \\
0.4\end{array}$ & $\begin{array}{l}99.6 \\
99.8 \\
99.6\end{array}$ & $\begin{array}{l}0 \\
0 \\
0 \\
\end{array}$ & & 0.52 & 1 \\
\hline
\end{tabular}


Table 7. Results of the Aug. 7 experiment with eggs of Anthocidaris crassspina. Wind NNE 1. Test water temperature: $28^{\circ} \mathrm{C}$.

\begin{tabular}{|c|c|c|c|c|c|c|c|c|c|c|}
\hline \multirow{2}{*}{$\begin{array}{l}\text { Location } \\
\text { (depth) }\end{array}$} & \multirow{2}{*}{$\begin{array}{c}\text { Fertiliz. } \\
\begin{array}{c}\text { membrane } \\
\text { formation }\end{array}\end{array}$} & \multicolumn{3}{|c|}{ First cleavage $(50 \mathrm{~min})}$. & \multicolumn{3}{|c|}{ Gastrulation (15 hrs.) } & \multicolumn{2}{|c|}{ Other notes } & \multirow{2}{*}{$\begin{array}{l}\text { Degree of } \\
\text { inhibitory } \\
\text { effect }\end{array}$} \\
\hline & & 1 cell & $\begin{array}{c}2 \text { cell } \\
(\text { normal })\end{array}$ & $\begin{array}{c}\text { multi-cell } \\
\text { (polysperm) }\end{array}$ & $\begin{array}{c}\text { permanent } \\
\text { blastula }\end{array}$ & $\begin{array}{c}\text { gastrula } \\
\text { (normal) }\end{array}$ & exogastrula & $\begin{array}{l}\text { abnormal } \\
\text { develop. }\end{array}$ & COD & \\
\hline \multirow{3}{*}{$\begin{array}{l}\text { Running } \\
\text { sea water of } \\
\text { Laboratory }\end{array}$} & $97.3 \%$ & $3.8 \%$ & $96.2 \%$ & $0 \%$ & $0.6 \%$ & $99.4 \%$ & $0 \%$ & & ppm & \multirow{3}{*}{1} \\
\hline & 93.8 & 8.1 & 91.5 & 0.4 & 0.5 & 99.5 & 0 & & & \\
\hline & 97.8 & 3.2 & 96.8 & 0 & 0.5 & 99.5 & 0 & & & \\
\hline \multirow{3}{*}{$\begin{array}{l}\text { Water from open sea } \\
\text { side fo Hatakejima } \\
\text { Surface }\end{array}$} & 98.2 & 3.4 & 96.6 & 0 & 0.7 & 99.3 & 0 & & & \multirow{3}{*}{1} \\
\hline & 94.2 & 6.3 & 93. 7 & 0 & 0.8 & 99.2 & 0 & & & \\
\hline & 96.3 & 4.1 & 95.9 & 0 & 0.6 & 99.4 & 0 & & & \\
\hline \multirow{3}{*}{ Bottom (25) } & 94.5 & 12.4 & 87.6 & 0 & 1.1 & 98.9 & 0 & & & \multirow{3}{*}{1} \\
\hline & 89.3 & 13.5 & 86.2 & 0.3 & 1.3 & 98.7 & 0 & & & \\
\hline & 91.3 & 9.7 & 90.3 & 0 & 0.9 & 99.1 & 0 & & & \\
\hline \multirow{3}{*}{$\begin{array}{l}\text { Water from land } \\
\text { side of Hatakejima } \\
\text { Surface }\end{array}$} & 93.4 & 11.3 & 88.7 & 0 & 0.8 & 99.2 & 0 & & & \multirow{3}{*}{1} \\
\hline & 87.3 & 15.3 & 84.7 & 0 & 0.9 & 99.1 & 0 & & & \\
\hline & 89.8 & 12.7 & 87.3 & 0 & 0.8 & 99.2 & 0 & & & \\
\hline \multirow{3}{*}{ Bottom (27) } & 92.3 & 15,6 & 84.4 & 0 & 1.3 & 98.7 & 0 & & & \multirow{3}{*}{2} \\
\hline & 84.3 & 18.9 & 80.4 & 0.7 & 1.5 & 98.5 & 0 & & & \\
\hline & 87.5 & 16.0 & 83.7 & 0.3 & 1.2 & 98.8 & 0 & & & \\
\hline \multirow{3}{*}{$\begin{array}{l}\text { Sea water from } \\
\text { Tsunashirazu cove } \\
\text { Surface }\end{array}$} & 87.5 & 17.8 & 82.2 & 0 & 6.3 & 93.7 & 0 & \multirow{3}{*}{$\begin{array}{l}\text { slightly } \\
\text { delay }\end{array}$} & & \multirow{3}{*}{2} \\
\hline & 89.8 & 12.1 & 87.3 & 0.6 & 18.3 & 81.7 & 0 & & & \\
\hline & 84.9 & 19.3 & 80.4 & 0.3 & 12.9 & 87.1 & 0 & & 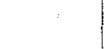 & \\
\hline \multirow{3}{*}{ Bottom (5) } & 83.2 & 21.3 & 78.0 & 0.7 & 5.3 & 94.7 & 0 & \multirow{3}{*}{$\begin{array}{l}\text { slightly } \\
\text { delay }\end{array}$} & & \multirow{3}{*}{2} \\
\hline & 81.3 & 19.5 & 79.9 & 0.6 & 7.2 & 92.8 & 0 & & & \\
\hline & 78.2 & 24.3 & 74.9 & 0.8 & 8.3 & 91.7 & 0 & & & \\
\hline
\end{tabular}


Table 8. Results of the Aug. 24 experiment with eggs of Anthocidaris crassispina.

Wind : 0 . Test water temperature: $25^{\circ} \mathrm{C}$.

\begin{tabular}{|c|c|c|c|c|c|c|c|c|c|c|}
\hline \multirow{2}{*}{$\begin{array}{l}\text { Location } \\
\text { (depth) }\end{array}$} & \multirow{2}{*}{$\mid$\begin{tabular}{c|} 
Fertiliz. \\
$\begin{array}{c}\text { membrane } \\
\text { formation }\end{array}$
\end{tabular}} & \multicolumn{3}{|c|}{ First cleavage (60 min.) } & \multicolumn{3}{|c|}{ Gastrulation (17 hrs.) } & \multicolumn{2}{|c|}{ Other notes } & \multirow{2}{*}{$\begin{array}{l}\text { Degree of } \\
\text { inhibitory } \\
\text { effect }\end{array}$} \\
\hline & & 1 cell & $\begin{array}{c}2 \text { cell } \\
\text { (normal) }\end{array}$ & $\begin{array}{c}\text { multi-cell } \\
\text { (polysperm) }\end{array}$ & $\begin{array}{c}\text { permanent } \\
\text { blastula }\end{array}$ & $\begin{array}{l}\text { gastrula } \\
\text { (normal) }\end{array}$ & exogastrula & $\begin{array}{l}\text { abnormal } \\
\text { develop. }\end{array}$ & COD & \\
\hline \multirow{3}{*}{$\begin{array}{l}\text { Running } \\
\text { sea water of } \\
\text { Laboratory }\end{array}$} & $99.3 \%$ & $0.9 \%$ & $98.3 \%$ & $0.8 \%$ & $0.7 \%$ & $99.3 \%$ & $0 \%$ & & ppm & \\
\hline & 98.3 & 1.2 & 98.1 & 0.7 & 0.8 & 99.2 & & & & 1 \\
\hline & 96.9 & 3.7 & 96.2 & 0.1 & 0.8 & 99.1 & 0.1 & & & \\
\hline \multirow{3}{*}{$\begin{array}{l}\text { Water from open sea } \\
\text { side of Hatakejima } \\
\text { Surface }\end{array}$} & 99.4 & $0: 8$ & 98.9 & 0.3 & 0.9 & 99.1 & 0 & & & \\
\hline & 99.0 & 1.1 & 98.1 & 0.8 & 0.9 & 99.1 & 0 & & & 1 \\
\hline & 96.8 & 3.5 & 96.3 & 0.2 & 1.0 & 99.0 & 0 & & & \\
\hline \multirow{3}{*}{ Bottom (25) } & 99.3 & 0.8 & 98.7 & 0.5 & 1.1 & 98.9 & 0 & & & \\
\hline & 98.9 & 1.2 & 97.9 & 0.9 & 1.4 & 98.6 & 0 & & & 1 \\
\hline & 96.8 & 3.6 & 96.1 & 0.3 & 1.7 & 98.3 & 0 & & & \\
\hline \multirow{3}{*}{$\begin{array}{l}\text { Water from land } \\
\text { side of Hatakejima } \\
\text { Surface }\end{array}$} & 92.2 & 9.0 & 90.1 & 0.9 & 1.9 & 98.1 & 0 & & & \\
\hline & 91.7 & 8.5 & 90.4 & 1.1 & 2.4 & 97.6 & 0 & & & 1 \\
\hline & 89.2 & 13.5 & 86.0 & 0.5 & 2.5 & 97.5 & 0 & & & \\
\hline \multirow{3}{*}{ Bottom (27) } & 88.5 & 11.8 & 87.4 & 0.8 & 2.7 & 97.3 & 0 & & & \\
\hline & 88.3 & 12.0 & 86.8 & 1.2 & 2.5 & 97.5 & 0 & & & 1 \\
\hline & 86.0 & 13,6 & 85.8 & 0.6 & 4.5 & 95.5 & 0 & & & \\
\hline \multirow{3}{*}{$\begin{array}{l}\text { Sea water from } \\
\text { Tsunashirazu cove } \\
\text { Surface }\end{array}$} & 88.3 & 11.7 & 87.5 & 0.8 & 2.9 & 97.1 & 0 & & & \\
\hline & 88.7 & 11.6 & 87.4 & 1.0 & 3.5 & 96.5 & 0 & & & 1 \\
\hline & 86.2 & 13.4 & 86.1 & 0.5 & 3.9 & 96.1 & 0 & & & \\
\hline \multirow{3}{*}{ Bottom (5) } & 87.9 & 12.3 & 86.5 & 1.2 & 2.7 & 97.3 & 0 & & & \\
\hline & 87.6 & 12.5 & 86.2 & 1.3 & 3.8 & 96.2 & 0 & & & 1 \\
\hline & 85.3 & 13.7 & 85.6 & 0.7 & 5.7 & 94.3 & 0 & & & . \\
\hline
\end{tabular}


Table 9. Results of the Sep. 23 experiment with eggs of Anthocidaris crassispina.

Wind: E 1. Test water temperature : $26^{\circ} \mathrm{C}$.

\begin{tabular}{|c|c|c|c|c|c|c|c|c|c|c|}
\hline \multirow{2}{*}{$\begin{array}{l}\text { Location } \\
\text { (depth) }\end{array}$} & \multirow{2}{*}{\begin{tabular}{|c|} 
Fertiliz. \\
$\begin{array}{c}\text { membrane } \\
\text { formation }\end{array}$ \\
\end{tabular}} & \multicolumn{3}{|c|}{ First cleavage $(60 \mathrm{~min})}$. & \multicolumn{3}{|c|}{ Gastrulation (17 hrs.) } & \multicolumn{2}{|c|}{ Other notes } & \multirow{2}{*}{$\begin{array}{l}\text { Degree of } \\
\text { inhibitory } \\
\text { effect }\end{array}$} \\
\hline & & 1 cell & $\begin{array}{c}2 \text { cell } \\
\text { (normal) }\end{array}$ & $\begin{array}{c}\text { multi-cell } \\
\text { (polysperm) }\end{array}$ & $\begin{array}{c}\text { permanent } \\
\text { blastula }\end{array}$ & $\begin{array}{c}\text { gastrula } \\
\text { (normal) }\end{array}$ & exogastrula & $\begin{array}{l}\text { abnormal } \\
\text { develop. }\end{array}$ & COD & \\
\hline \multirow{2}{*}{$\begin{array}{l}\text { Running } \\
\text { sea water of } \\
\text { Laboratory }\end{array}$} & $91.5 \%$ & $11.5 \%$ & $88.5 \%$ & $0 \%$ & $0.5 \%$ & $99.5 \%$ & $0 \%$ & & ppm & 1 \\
\hline & 87.5 & 15.0 & 85.0 & 0 & 1.0 & 99.0 & 0 & & & \\
\hline \multirow{2}{*}{$\begin{array}{l}\text { Water from open sea } \\
\text { side of Hatakejima } \\
\text { Surface }\end{array}$} & 86.5 & 14.5 & 85.5 & 0 & 2.0 & 98.0 & 0 & & \multirow{2}{*}{1.96} & \multirow{2}{*}{1} \\
\hline & 85.5 & 17.0 & 83,0 & 0 & 2.0 & 98.0 & 0 & & & \\
\hline \multirow{2}{*}{ Bottom (25) } & 86.0 & 16.0 & 84.0 & 0 & 2.0 & 98.0 & 0 & & \multirow{2}{*}{1.81} & \multirow{2}{*}{1} \\
\hline & 85.0 & 17.5 & 82.5 & 0 & 3.5 & 96.5 & 0 & & & \\
\hline \multirow{2}{*}{$\begin{array}{l}\text { Water from land } \\
\text { side of Hatakejima } \\
\text { Surface }\end{array}$} & 85.0 & 19.5 & 80.5 & 0 & 2.0 & 98.0 & 0 & & \multirow{2}{*}{2.04} & \multirow{2}{*}{1} \\
\hline & 85.0 & 20.0 & 80.0 & 0 & 2.5 & 97.5 & 0 & & & \\
\hline \multirow{2}{*}{ Bottom (27) } & 84.5 & 20.0 & 80.0 & 0 & 2.5 & 97.5 & 0 & & \multirow{2}{*}{2.18} & \multirow{2}{*}{1} \\
\hline & 83.5 & 21.0 & 79. 0 & 0 & 3.5 & 96.5 & 0 & & & \\
\hline \multirow{2}{*}{$\begin{array}{l}\text { Sea water from } \\
\text { Tsunashirazu cove } \\
\text { Surface }\end{array}$} & 85.5 & 19. 5 & 80.5 & 0 & 2.5 & 97.5 & 0 & & \multirow{2}{*}{2.29} & \multirow{2}{*}{1} \\
\hline & 85.0 & 20.0 & 80.0 & 0 & 3. 0 & 97.0 & 0 & & & \\
\hline \multirow{2}{*}{ Bottom (5) } & 83.0 & 21.0 & 79.0 & 0 & 3. 5 & 96.5 & 0 & & \multirow{2}{*}{1.51} & \multirow{2}{*}{2} \\
\hline & 82.5 & 22.5 & 77.5 & 0 & 4.0 & 96.0 & 0 & & & \\
\hline
\end{tabular}


Table 10. Results of the Nov. 23 experiment with eggs of Pseudocentrotus depressus.

Wind : NW 1. Test water temperature: $14^{\circ} \mathrm{C}$.

\begin{tabular}{|c|c|c|c|c|c|c|c|c|c|c|}
\hline \multirow{2}{*}{$\begin{array}{l}\text { Location } \\
\text { (depth) }\end{array}$} & \multirow{2}{*}{$\frac{\text { Fertiliz. }}{\begin{array}{c}\text { membrane } \\
\text { formation }\end{array}}$} & \multicolumn{3}{|c|}{ First cleavage $(120 \mathrm{~min})}$. & \multicolumn{3}{|c|}{ Gastrulation (24 hrs.) } & \multicolumn{2}{|c|}{ Other notes } & \multirow{2}{*}{$\begin{array}{l}\text { Degree of } \\
\text { inhibitory } \\
\text { effect }\end{array}$} \\
\hline & & 1 cell & $\left|\begin{array}{c}2 \text { cell } \\
(\text { normal })\end{array}\right|$ & $\begin{array}{c}\text { multi-cell } \\
\text { (polysperm) }\end{array}$ & $\begin{array}{c}\text { permanent } \\
\text { blastula }\end{array}$ & $\begin{array}{l}\text { gastrula } \\
\text { (normal) }\end{array}$ & exogastrula & $\left|\begin{array}{l}\text { abnormal } \\
\text { develop. }\end{array}\right|$ & $\mathrm{COD}$ & \\
\hline $\begin{array}{l}\text { Running } \\
\text { sea water of } \\
\text { Laboratory }\end{array}$ & $\begin{array}{l}98.3 \% \\
99.7\end{array}$ & $\begin{array}{l}0.8 \% \\
0.4\end{array}$ & $\begin{array}{l}98.0 \% \\
99.6\end{array}$ & $\begin{array}{l}1.2 \% \\
0\end{array}$ & $\begin{array}{l}0.2 \% \\
0.1\end{array}$ & $\begin{array}{l}99.8 \% \\
99.9\end{array}$ & $\begin{array}{ll}0 & \% \\
0 & \end{array}$ & & $\begin{array}{l}\mathrm{ppm} \\
0.81\end{array}$ & 1 \\
\hline $\begin{array}{l}\text { Water from open sea } \\
\text { side of Hatakejima } \\
\text { Surface }\end{array}$ & $\begin{array}{l}98.5 \\
99.5\end{array}$ & $\begin{array}{l}1.1 \\
0.6\end{array}$ & $\begin{array}{l}98.2 \\
99.2\end{array}$ & $\begin{array}{l}0.7 \\
0.2\end{array}$ & $\begin{array}{l}0.3 \\
0.2\end{array}$ & $\begin{array}{l}99.7 \\
99.8\end{array}$ & $\begin{array}{l}0 \\
0\end{array}$ & & 1.08 & 1 \\
\hline Bottom (25) & $\begin{array}{l}96.9 \\
99.6\end{array}$ & $\begin{array}{l}2.4 \\
0.4\end{array}$ & $\begin{array}{l}96.3 \\
99.4\end{array}$ & $\begin{array}{l}1.3 \\
0.2\end{array}$ & $\begin{array}{l}0.3 \\
0.2\end{array}$ & $\begin{array}{l}99.7 \\
99.8\end{array}$ & $\begin{array}{l}0 \\
0\end{array}$ & & 0.85 & 1 \\
\hline $\begin{array}{l}\text { Water from land } \\
\text { side of Hatakejima } \\
\text { Surface }\end{array}$ & $\begin{array}{l}96.7 \\
99.5\end{array}$ & $\begin{array}{l}1.8 \\
0.3\end{array}$ & $\begin{array}{l}96.5 \\
99.4\end{array}$ & $\begin{array}{l}1.7 \\
0.3\end{array}$ & $\begin{array}{l}0.4 \\
0.1\end{array}$ & $\begin{array}{l}99.6 \\
99.9\end{array}$ & $\begin{array}{l}0 \\
0\end{array}$ & & 0.61 & 1 \\
\hline Bottom (27) & $\begin{array}{l}96.5 \\
99.2\end{array}$ & $\begin{array}{l}2.3 \\
0.6\end{array}$ & $\begin{array}{l}95.8 \\
99.0\end{array}$ & $\begin{array}{l}1.9 \\
0.4\end{array}$ & $\begin{array}{l}0.3 \\
0.2\end{array}$ & $\begin{array}{l}99.7 \\
99.8\end{array}$ & $\begin{array}{l}0 \\
0\end{array}$ & & 1. 16 & 1 \\
\hline $\begin{array}{l}\text { Sea water from } \\
\text { Tsunashirazu cove } \\
\text { Surface }\end{array}$ & $\begin{array}{l}96.3 \\
99.3\end{array}$ & $\begin{array}{l}2.4 \\
0.4\end{array}$ & $\begin{array}{l}95.5 \\
99.2\end{array}$ & $\begin{array}{l}2.1 \\
0.4\end{array}$ & $\begin{array}{l}0.4 \\
0.2\end{array}$ & $\begin{array}{l}99.6 \\
99.8\end{array}$ & $\begin{array}{l}0 \\
0\end{array}$ & & 1.29 & 1 \\
\hline Bottom (5) & $\begin{array}{l}96.2 \\
99.3\end{array}$ & $\begin{array}{l}2.6 \\
0.7\end{array}$ & $\begin{array}{l}95.0 \\
98.9\end{array}$ & $\begin{array}{l}2.4 \\
0.4\end{array}$ & $\begin{array}{l}0.5 \\
0.3\end{array}$ & $\begin{array}{l}99.5 \\
99.7\end{array}$ & $\begin{array}{l}0 \\
0\end{array}$ & & 1.07 & 1 \\
\hline
\end{tabular}


Table 11. Results of the Feb. 21 experiment with eggs of Hemicentrotus pulcherrimus.

Wind ; NW 1. Test water temperature; $17^{\circ} \mathrm{C}$ (warmed).

0 hr. old eggs

\begin{tabular}{|c|c|c|c|c|c|c|c|c|c|c|}
\hline \multirow{2}{*}{$\begin{array}{l}\text { Location } \\
\text { (depth) }\end{array}$} & \multirow{2}{*}{\begin{tabular}{|c|} 
Fertiliz. \\
$\begin{array}{c}\text { membrane } \\
\text { formation }\end{array}$
\end{tabular}} & \multicolumn{3}{|c|}{ First cleavage $(90 \mathrm{~min})}$. & \multicolumn{3}{|c|}{ Gastrulation ( $24 \mathrm{hrs}$.) } & \multicolumn{2}{|c|}{ Other notes } & \multirow{2}{*}{$\begin{array}{l}\text { Degree of } \\
\text { inhibitory } \\
\text { effect I }\end{array}$} \\
\hline & & 1 cell & $\begin{array}{c}2 \text { cell } \\
\text { (normal) }\end{array}$ & $\left(\begin{array}{c}\text { multi-cell } \\
\text { (polyspermy) }\end{array}\right.$ & \begin{tabular}{|c|} 
permanent \\
blastula
\end{tabular} & \begin{tabular}{|c|} 
gastrula \\
(normal)
\end{tabular} & exogastrula & $\begin{array}{l}\text { abnormal } \\
\text { develop. }\end{array}$ & $\mathrm{COD}$ & \\
\hline $\begin{array}{l}\text { Running } \\
\text { sea water of } \\
\text { Laboratory }\end{array}$ & $\begin{array}{l}99.5 \% \\
99.0 \\
97.5\end{array}$ & $\begin{array}{l}1.0 \% \\
2.0 \\
3.5\end{array}$ & $\begin{array}{l}99.0 \% \\
98.0 \\
96.5 \\
\end{array}$ & \begin{tabular}{ll|}
0 & $\%$ \\
0 & \\
0 & \\
\end{tabular} & $\begin{array}{l}0.5 \% \\
0.5 \\
0\end{array}$ & $\begin{array}{l}99.5 \% \\
99.5 \\
100\end{array}$ & $\begin{array}{ll}0 & \% \\
0 & \\
0 & \end{array}$ & & $\begin{array}{l}\text { ppm } \\
1.07\end{array}$ & 1 \\
\hline $\begin{array}{l}\text { Water from open sea } \\
\text { side of Hatakejima } \\
\text { Surface }\end{array}$ & $\begin{array}{l}98.5 \\
97.5 \\
99.0\end{array}$ & $\begin{array}{l}2.0 \\
2.5 \\
1.0\end{array}$ & $\begin{array}{l}98.0 \\
97.5 \\
99.0\end{array}$ & $\begin{array}{l}0 \\
0 \\
0\end{array}$ & $\begin{array}{l}1.0 \\
1.5 \\
0.5\end{array}$ & $\begin{array}{l}99.0 \\
98.5 \\
99.5\end{array}$ & $\begin{array}{l}0 \\
0 \\
0\end{array}$ & & 1.09 & 1 \\
\hline Bottom (25) & $\begin{array}{l}98.0 \\
96.5 \\
99.5\end{array}$ & $\begin{array}{l}2.5 \\
3.0 \\
4.0\end{array}$ & $\begin{array}{l}97.5 \\
97.0 \\
96.0\end{array}$ & $\begin{array}{l}0 \\
0 \\
0\end{array}$ & $\begin{array}{l}1.0 \\
1.0 \\
1.5\end{array}$ & $\begin{array}{l}99.0 \\
99.0 \\
98.5\end{array}$ & $\begin{array}{l}0 \\
0 \\
0\end{array}$ & & 0.84 & 1 \\
\hline $\begin{array}{l}\text { Water from land } \\
\text { side of Hatakejima } \\
\text { Surface }\end{array}$ & $\begin{array}{l}98.0 \\
97.0 \\
97.5\end{array}$ & $\begin{array}{l}3.0 \\
4.0 \\
4.5\end{array}$ & $\begin{array}{l}97.0 \\
96.0 \\
95.5\end{array}$ & $\begin{array}{l}0 \\
0 \\
0\end{array}$ & $\begin{array}{l}1.5 \\
1.0 \\
2.5\end{array}$ & $\begin{array}{l}98.5 \\
99.0 \\
97.5\end{array}$ & $\begin{array}{l}0 \\
0 \\
0\end{array}$ & & 1.13 & 1 \\
\hline Bottom (27) & $\begin{array}{l}97.0 \\
95.0 \\
93.0\end{array}$ & $\begin{array}{l}7.5 \\
5.5 \\
9.0\end{array}$ & $\begin{array}{l}92.5 \\
94.5 \\
91.0\end{array}$ & $\begin{array}{l}0 \\
0 \\
0\end{array}$ & $\begin{array}{l}2.5 \\
1.5 \\
3.0\end{array}$ & $\begin{array}{l}97.5 \\
98.5 \\
97.0\end{array}$ & $\begin{array}{l}0 \\
0 \\
0\end{array}$ & & 1.33 & 1 \\
\hline $\begin{array}{l}\text { Sea water from } \\
\text { Tsunashirazu cove } \\
\text { Surface }\end{array}$ & $\begin{array}{l}93.5 \\
94.0 \\
91.5\end{array}$ & $\begin{array}{l}16.5 \\
14.5 \\
12.0\end{array}$ & $\begin{array}{l}83.5 \\
85.5 \\
88.0\end{array}$ & $\begin{array}{l}0 \\
0 \\
0\end{array}$ & $\begin{array}{l}2.0 \\
3.0 \\
4.5\end{array}$ & $\begin{array}{l}98.0 \\
97.0 \\
95.5\end{array}$ & $\begin{array}{l}0 \\
0 \\
0\end{array}$ & & 1.30 & 1 \\
\hline Bottom (5) & $\begin{array}{l}94.5 \\
93.5 \\
93.0\end{array}$ & $\begin{array}{l}15.5 \\
17.0 \\
15.5\end{array}$ & $\begin{array}{l}84.5 \\
83.0 \\
84.5\end{array}$ & $\begin{array}{l}0 \\
0 \\
0\end{array}$ & $\begin{array}{l}4.0 \\
4.5 \\
3.0\end{array}$ & $\begin{array}{l}96.0 \\
95.5 \\
97.0\end{array}$ & $\begin{array}{l}0 \\
0 \\
0\end{array}$ & & 1.01 & 1 \\
\hline
\end{tabular}


Table 11. (continued).

\begin{tabular}{|c|c|c|c|c|c|c|c|c|c|c|}
\hline \multirow{2}{*}{$\begin{array}{l}\text { Location } \\
\text { (depth) }\end{array}$} & \multirow{2}{*}{$\begin{array}{c}\text { Fertiliz. } \\
\text { membrane } \\
\text { formation }\end{array}$} & \multicolumn{3}{|c|}{ First cleavage (90 min.) } & \multicolumn{3}{|c|}{ Gastrulation ( 24 hrs.) } & \multicolumn{2}{|c|}{ Other notes } & \multirow{2}{*}{$\begin{array}{l}\text { Degree of } \\
\text { inhibitory } \\
\text { effect II }\end{array}$} \\
\hline & & 1 cell & $\begin{array}{c}2 \text { cell } \\
\text { (normal) }\end{array}$ & $\left|\begin{array}{c}\text { multi-cell } \\
\text { (polyspermy) }\end{array}\right|$ & $\begin{array}{c}\text { permanent } \\
\text { blastula }\end{array}$ & $\begin{array}{c}\text { gastrula } \\
\text { (normal) }\end{array}$ & exogastrula & $\begin{array}{l}\text { abnormal } \\
\text { develop. }\end{array}$ & COD & \\
\hline $\begin{array}{l}\text { Running } \\
\text { sea water of } \\
\text { Laboratory }\end{array}$ & $\begin{array}{l}99.0 \% \\
98.5 \\
96.0\end{array}$ & $\begin{array}{l}2.0 \% \\
3.0 \\
5.0\end{array}$ & $\begin{array}{l}98.0 \\
97.0 \\
95.0\end{array}$ & $\begin{array}{ll}0 & \% \\
0 & \\
0 & \end{array}$ & $\begin{array}{l}0.5 \% \\
1.0 \\
0.5\end{array}$ & $\begin{array}{l}99.5 \% \\
99.0 \\
99.5\end{array}$ & $\begin{array}{ll}0 & \mathscr{O} \\
0 & \\
0 & \end{array}$ & & ppm & 0 \\
\hline $\begin{array}{l}\text { Water from open sea } \\
\text { side of Hatakejima } \\
\text { Surface }\end{array}$ & $\begin{array}{l}94.5 \\
93.5 \\
93.0\end{array}$ & $\begin{array}{l}6.0 \\
7.5 \\
8.5\end{array}$ & $\begin{array}{l}93.5 \\
92.5 \\
91.5\end{array}$ & $\begin{array}{l}0.5 \\
0 \\
0\end{array}$ & $\begin{array}{l}1.0 \\
1.0 \\
0.5\end{array}$ & $\begin{array}{l}99.0 \\
99.0 \\
99.5\end{array}$ & $\begin{array}{l}0 \\
0 \\
0\end{array}$ & & 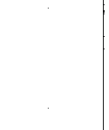 & 0 \\
\hline Bottom (25) & $\begin{array}{l}96.0 \\
94.0 \\
93.5\end{array}$ & $\begin{array}{l}8.5 \\
8.0 \\
7.0\end{array}$ & $\begin{array}{l}91.5 \\
92.0 \\
93.0\end{array}$ & $\begin{array}{l}0 \\
0 \\
0\end{array}$ & $\begin{array}{l}0.5 \\
1.0 \\
1.0\end{array}$ & $\begin{array}{l}99.5 \\
99.0 \\
99.0\end{array}$ & $\begin{array}{l}0 \\
0 \\
0\end{array}$ & & & 0 \\
\hline $\begin{array}{l}\text { Water from land } \\
\text { side of Hatakejima } \\
\text { Surface }\end{array}$ & $\begin{array}{l}92.0 \\
90.5 \\
89.5\end{array}$ & $\begin{array}{l}23.0 \\
25.0 \\
23.5\end{array}$ & $\begin{array}{l}77.0 \\
75.0 \\
76.5\end{array}$ & $\begin{array}{l}0 \\
0 \\
0\end{array}$ & $\begin{array}{l}5.5 \\
6.5 \\
6.0\end{array}$ & $\begin{array}{l}94.5 \\
93.5 \\
94.0\end{array}$ & $\begin{array}{l}0 \\
0 \\
0\end{array}$ & & & 2 \\
\hline Bottom (27) & $\begin{array}{l}93.5 \\
89.0 \\
87.5\end{array}$ & $\begin{array}{l}20.5 \\
25.5 \\
24.0\end{array}$ & $\begin{array}{l}79.5 \\
74.5 \\
76.0\end{array}$ & $\begin{array}{l}0 \\
0 \\
0\end{array}$ & $\begin{array}{l}8.0 \\
8.5 \\
6.5\end{array}$ & $\begin{array}{l}92.0 \\
91.5 \\
93.5\end{array}$ & $\begin{array}{l}0 \\
0 \\
0\end{array}$ & & & 2 \\
\hline $\begin{array}{l}\text { sea water from } \\
\text { Tsunashirazu cove } \\
\text { Surface }\end{array}$ & $\begin{array}{l}87.0 \\
83.5 \\
84.0\end{array}$ & $\begin{array}{l}28.0 \\
29.5 \\
29.0\end{array}$ & $\begin{array}{l}72.0 \\
70.5 \\
71.0\end{array}$ & $\begin{array}{l}0 \\
0 \\
0\end{array}$ & $\begin{array}{l}7.5 \\
8.5 \\
7.0\end{array}$ & $\begin{array}{l}92.5 \\
91.5 \\
93.0\end{array}$ & $\begin{array}{l}0 \\
0 \\
0\end{array}$ & & & 2 \\
\hline Bottom (5) & $\begin{array}{l}91.0 \\
89.5 \\
87.5\end{array}$ & $\begin{array}{l}26.5 \\
26.0 \\
28.0\end{array}$ & $\begin{array}{l}72.5 \\
73.5 \\
71.0\end{array}$ & $\begin{array}{l}1.0 \\
0.5 \\
1.0\end{array}$ & $\begin{array}{l}8.5 \\
7.5 \\
8.5\end{array}$ & $\begin{array}{l}91.5 \\
92.5 \\
91.5\end{array}$ & $\begin{array}{l}0 \\
0 \\
0\end{array}$ & & & 2 \\
\hline
\end{tabular}


Table 12. Results of the Mar. 20 experiment with eggs of Hemicentrotus pulcherrimus.

Wind; 0 . Test water temperature; $15^{\circ} \mathrm{C}$.

0 hr. old eggs

\begin{tabular}{|c|c|c|c|c|c|c|c|c|c|c|}
\hline \multirow{2}{*}{$\begin{array}{l}\text { Location } \\
\text { (depth) }\end{array}$} & \multirow{2}{*}{$\begin{array}{c}\text { Fertiliz. } \\
\text { membrane } \\
\text { formation }\end{array}$} & \multicolumn{3}{|c|}{ First cleavage $(150 \mathrm{~min})}$. & \multicolumn{3}{|c|}{ Gastrulation ( 32 hrs.) } & \multicolumn{2}{|c|}{ Other notes } & \multirow{2}{*}{$\begin{array}{l}\text { Degree of } \\
\text { inhibitory } \\
\text { effect I }\end{array}$} \\
\hline & & 1 cell & $\begin{array}{c}2 \text { cell } \\
\text { (normal) }\end{array}$ & $\begin{array}{c}\text { multi-cell } \\
\text { (polyspermy) }\end{array}$ & $\begin{array}{c}\text { permanent } \\
\text { blastula }\end{array}$ & $\begin{array}{c}\text { gastrula } \\
\text { (normal) }\end{array}$ & exogastrula & $\begin{array}{c}\text { abnormal } \\
\text { develop. }\end{array}$ & COD & \\
\hline $\begin{array}{l}\text { Running } \\
\text { sea water of } \\
\text { Laboratory }\end{array}$ & $\begin{array}{c}99.5 \% \\
100 \\
97.0\end{array}$ & $\begin{array}{l}1.0 \% \\
0 \\
4.0\end{array}$ & $\begin{array}{c}98.5 \% \\
100 \\
96.0\end{array}$ & $\begin{array}{l}0.5 \% \\
0 \\
0\end{array}$ & $\begin{array}{l}0.5 \% \\
1.0 \\
0.5\end{array}$ & $\begin{array}{l}99.5 \% \\
99.0 \\
99.5\end{array}$ & $\begin{array}{ll}0 & \not 6 \\
0 & \\
0 & \end{array}$ & & ppm & 1 \\
\hline $\begin{array}{l}\text { Water from open sea } \\
\text { side of Hatakejima } \\
\text { Surface }\end{array}$ & $\begin{array}{l}99.5 \\
99.5 \\
98.0\end{array}$ & $\begin{array}{l}1.0 \\
2.0 \\
3.0\end{array}$ & $\begin{array}{l}99.0 \\
98.0 \\
97.0\end{array}$ & $\begin{array}{l}0 \\
0 \\
0\end{array}$ & $\begin{array}{l}1.0 \\
0 \\
0.5\end{array}$ & $\begin{array}{l}99.0 \\
100 \\
99.5\end{array}$ & $\begin{array}{l}0 \\
0 \\
0\end{array}$ & & & 1 \\
\hline Bottom (25) & $\begin{array}{l}97.5 \\
100 \\
94.0\end{array}$ & $\begin{array}{l}4.5 \\
2.0 \\
8.0\end{array}$ & $\begin{array}{l}95.5 \\
98.0 \\
92.0\end{array}$ & $\begin{array}{l}0 \\
0 \\
0\end{array}$ & $\begin{array}{l}1.0 \\
0.5 \\
1.0\end{array}$ & $\begin{array}{l}99.0 \\
99.5 \\
99.0\end{array}$ & $\begin{array}{l}0 \\
0 \\
0\end{array}$ & & & 1 \\
\hline $\begin{array}{l}\text { Water from land } \\
\text { side of Hatakejima } \\
\text { Surface }\end{array}$ & $\begin{array}{l}98.0 \\
99.0 \\
95.0\end{array}$ & $\begin{array}{l}2.5 \\
1.5 \\
9.0\end{array}$ & $\begin{array}{l}97.5 \\
98.5 \\
91.0\end{array}$ & $\begin{array}{l}0 \\
0 \\
0\end{array}$ & $\begin{array}{l}1.0 \\
1.0 \\
1.5\end{array}$ & $\begin{array}{l}99.0 \\
99.0 \\
98.5\end{array}$ & $\begin{array}{l}0 \\
0 \\
0\end{array}$ & & & 1 \\
\hline Bottom (27) & $\begin{array}{l}96.5 \\
98.0 \\
95.5\end{array}$ & $\begin{array}{l}4.5 \\
2.5 \\
8.5\end{array}$ & $\begin{array}{l}94.0 \\
97.5 \\
91.5\end{array}$ & $\begin{array}{l}1.5 \\
0 \\
0\end{array}$ & $\begin{array}{l}1.0 \\
1.5 \\
2.0\end{array}$ & $\begin{array}{l}99.0 \\
98.5 \\
98.0\end{array}$ & $\begin{array}{l}0 \\
0 \\
0\end{array}$ & & & 1 \\
\hline $\begin{array}{l}\text { Sea water from } \\
\text { Tsunashirazu cove } \\
\text { Surface }\end{array}$ & $\begin{array}{l}96.0 \\
98.0 \\
95.0\end{array}$ & $\begin{array}{l}6.5 \\
5.0 \\
8.0\end{array}$ & $\begin{array}{l}93.5 \\
95.0 \\
92.0\end{array}$ & $\begin{array}{l}0 \\
0 \\
0\end{array}$ & $\begin{array}{l}1.0 \\
2.0 \\
2.0\end{array}$ & $\begin{array}{l}99.0 \\
98.0 \\
98.0\end{array}$ & $\begin{array}{l}0 \\
0 \\
0\end{array}$ & & & 1 \\
\hline Bottom (5) & $\begin{array}{l}96.5 \\
97.5 \\
96.0\end{array}$ & $\begin{array}{r}4.0 \\
3.5 \\
13.0\end{array}$ & $\begin{array}{l}96.0 \\
96.5 \\
87.0\end{array}$ & $\begin{array}{l}0 \\
0 \\
0\end{array}$ & $\begin{array}{l}1.5 \\
2.0 \\
2.0\end{array}$ & $\begin{array}{l}98.5 \\
98.0 \\
98.0\end{array}$ & $\begin{array}{l}0 \\
0 \\
0\end{array}$ & & & 1 \\
\hline
\end{tabular}


Table 12. (continued).

\begin{tabular}{|c|c|c|c|c|c|c|c|c|c|c|}
\hline \multirow{2}{*}{$\begin{array}{l}\text { Location } \\
\text { (depth) }\end{array}$} & \multirow{2}{*}{$\begin{array}{c}\text { Fertiliz. } \\
\begin{array}{c}\text { membrane } \\
\text { formation }\end{array}\end{array}$} & \multicolumn{3}{|c|}{ First cleavage $(150 \mathrm{~min})}$. & \multicolumn{3}{|c|}{ Gastrulation (32 hrs.) } & \multicolumn{2}{|c|}{ Other notes } & \multirow{2}{*}{$\begin{array}{l}\text { Degree of } \\
\text { inhibitory } \\
\text { effect II }\end{array}$} \\
\hline & & 1 cell & $\begin{array}{c}2 \text { cell } \\
(\text { normal })\end{array}$ & $\left|\begin{array}{c}\text { multi-cell } \\
\text { (polyspermy) }\end{array}\right|$ & $\begin{array}{c}\text { permanent } \\
\text { blastula }\end{array}$ & $\begin{array}{c}\text { gastrula } \\
\text { (normal) }\end{array}$ & exogastrula & $\begin{array}{c}\text { abnormal } \\
\text { develop. }\end{array}$ & COD & \\
\hline Running & $94.0 \%$ & $8.0 \%$ & $90.0 \%$ & 2.0 & $0.5 \%$ & $99.5 \%$ & $0 \%$ & & ppm & \\
\hline sea water of & 95.5 & 6.0 & 93,0 & 1.0 & 0.5 & 99.5 & 0 & & & 1 \\
\hline Laboratory & 93.0 & 9.0 & 91.0 & 0 & 1.0 & 99.0 & 0 & & & \\
\hline Water from open sea & 92.5 & 10.5 & 88.5 & 1.0 & 1.0 & 99.0 & 0 & & & \\
\hline side of Hatakejima & 94.5 & 8.0 & 91.5 & 0.5 & 1.5 & 98.5 & 0 & & & 1 \\
\hline Surface & 91.0 & 11.0 & 89.0 & 0 & 1.0 & 99.0 & 0 & & & \\
\hline \multirow{3}{*}{ Bottom (25) } & 91.0 & 13.5 & 84.5 & 2.0 & 2.0 & 98.0 & 0 & & & \multirow{3}{*}{1} \\
\hline & 92.5 & 13.0 & 86.0 & 1.0 & 2.5 & 97.5 & 0 & & & \\
\hline & 90.0 & 15.0 & 85.0 & 0 & 2.5 & 97.5 & 0 & & & \\
\hline Water from land & 91.5 & 18.5 & 80.0 & 1.5 & 4.5 & 95.5 & 0 & & & \\
\hline side of Hatakejima & 92.5 & 16.5 & 82.5 & 1.0 & 5.5 & 94.5 & 0 & & & 2 \\
\hline Surface & 88.5 & 20.5 & 79.0 & 0.5 & 4.0 & 96.0 & 0 & & & \\
\hline \multirow{3}{*}{ Bottom (27) } & 89.5 & 21.0 & 78.0 & 1.0 & 5.0 & 95.0 & 0 & & & \multirow{3}{*}{2} \\
\hline & 90.5 & 19.0 & 80.0 & 1.0 & 5.0 & 95.0 & 0 & & & \\
\hline & 88.0 & 24.0 & 76.0 & 0 & 5.5 & 94.5 & 0 & & & \\
\hline Sea water from & 88.0 & 29.5 & 69.5 & 1.0 & 7.5 & 92.5 & 0 & & & \\
\hline Tsunashirazu cove & 89.5 & 27.0 & 72.5 & 0.5 & 8.0 & 92.0 & 0 & & & 3 \\
\hline Surface & 85.5 & 30.5 & 69.5 & 0 & 7.0 & 93.0 & 0 & & & \\
\hline \multirow{3}{*}{ Bottom (5) } & 87.5 & 24.5 & 74.0 & 1.5 & 8.0 & 92.0 & 0 & & & \multirow{3}{*}{3} \\
\hline & 89.0 & 29.0 & 70.0 & 1.0 & 9.5 & 90.5 & 0 & & & \\
\hline & 82.5 & 30.5 & 69.5 & 0 & 11.0 & 89.0 & 0 & & & \\
\hline
\end{tabular}


Table 13. Results of the May 4 experiment with eggs of Anthocidaris crassispina.

Wind ; 0 . Test water temperature ; $16^{\circ} \mathrm{C}$.

hr. old eggs

\begin{tabular}{|c|c|c|c|c|c|c|c|c|c|c|}
\hline \multirow{2}{*}{$\begin{array}{l}\text { Location } \\
\text { (depth) }\end{array}$} & \multirow{2}{*}{\begin{tabular}{|c|} 
Fertiliz. \\
membrane \\
formation
\end{tabular}} & \multicolumn{3}{|c|}{ First cleavage $(120 \mathrm{~min})}$. & \multicolumn{3}{|c|}{ Gastrulation ( $30 \mathrm{hrs}$ ) } & \multicolumn{2}{|c|}{ Other notes } & \multirow{2}{*}{$\begin{array}{l}\text { Degree of } \\
\text { inhibitory } \\
\text { effect I }\end{array}$} \\
\hline & & 1 cell & $\begin{array}{c}2 \text { cell } \\
\text { (normal) }\end{array}$ & $\begin{array}{c}\text { multi-cell } \\
\text { (polyspermy) }\end{array}$ & $\begin{array}{c}\text { permanent } \\
\text { blastula }\end{array}$ & $\begin{array}{l}\text { gastrula } \\
\text { (normal) }\end{array}$ & exogastrula & $\begin{array}{l}\text { abnormal } \\
\text { develop. }\end{array}$ & COD & \\
\hline \multirow{3}{*}{$\begin{array}{l}\text { Running } \\
\text { sea water of } \\
\text { Laboratory }\end{array}$} & $93.5 \%$ & $8.0 \%$ & $92,0 \%$ & $0 \%$ & $1.0 \%$ & $99.0 \%$ & $0 \%$ & & \multirow{3}{*}{$\begin{array}{r}\text { ppm } \\
0.66\end{array}$} & \multirow{3}{*}{1} \\
\hline & 98.5 & 3.0 & 97.0 & 0 & 0.5 & 99.5 & 0 & & & \\
\hline & 99.0 & 2.0 & 97.5 & 0.5 & 0.5 & 99.5 & 0 & & & \\
\hline \multirow{3}{*}{$\begin{array}{l}\text { Water from open sea } \\
\text { side of Hatakejima } \\
\text { Surface }\end{array}$} & 94.5 & 7.0 & 93.0 & 0 & 0.5 & 99.5 & 0 & & \multirow{3}{*}{0.81} & \multirow{3}{*}{1} \\
\hline & 96.5 & 5.5 & 94.5 & 0 & 0 & 100 & 0 & & & \\
\hline & 97.5 & 4.0 & 96.0 & 0 & 0.5 & 99.5 & 0 & & & \\
\hline \multirow{3}{*}{ Bottom (25) } & 92.0 & 8.5 & 91.5 & 0 & 1.0 & 99.0 & 0 & & \multirow{3}{*}{1.11} & \multirow{3}{*}{1} \\
\hline & 97.0 & 4.5 & 95.5 & 0 & 0.5 & 99.5 & 0 & & & \\
\hline & 95.5 & 6.0 & 94.0 & 0 & 0.5 & 99.5 & 0 & & & \\
\hline \multirow{3}{*}{$\begin{array}{l}\text { Water from land } \\
\text { side of Hatakejima } \\
\text { Surface }\end{array}$} & 91.0 & 10.0 & 89.5 & 0.5 & 1.0 & 99.0 & 0 & & \multirow{3}{*}{1.65} & \multirow{3}{*}{1} \\
\hline & 90.0 & 10.5 & 88.0 & 1.5 & 1.5 & 98.5 & 0 & & & \\
\hline & 93.0 & 8.5 & 91.5 & 0 & 1.5 & 98.5 & 0 & & & \\
\hline \multirow{3}{*}{ Bottom (27) } & 89.5 & 13.0 & 87.0 & 0 & 1.5 & 98.5 & 0 & & \multirow{3}{*}{2.09} & \multirow{3}{*}{1} \\
\hline & 90.5 & 11.0 & 89.0 & 0 & 1.5 & 98.5 & 0 & & & \\
\hline & 91.5 & 11.0 & 89.0 & 0 & 2.0 & 98.0 & 0 & & & \\
\hline \multirow{3}{*}{$\begin{array}{l}\text { Sea water from } \\
\text { Tsunashirazu cove } \\
\text { Surface }\end{array}$} & 87.0 & 16.0 & 84.0 & 0 & 2.0 & 98.0 & 0 & & \multirow{3}{*}{0.72} & \multirow{3}{*}{1} \\
\hline & 88.5 & 14.0 & 86.0 & 0 & 2.5 & 97.5 & 0 & & & \\
\hline & 87.5 & 14.5 & 85.5 & 0 & 2.0 & 98.0 & 0 & & & \\
\hline \multirow{3}{*}{ Bottom (5) } & 86.5 & 15.5 & 84.5 & 0 & 2.0 & 98.0 & 0 & & \multirow{3}{*}{1.05} & \multirow{3}{*}{1} \\
\hline & 89.0 & 14.5 & 85.5 & 0 & 2.0 & 98.0 & 0 & & & \\
\hline & 90.0 & 14.0 & 86.0 & 0 & 2.5 & 97.5 & 0 & & & \\
\hline
\end{tabular}


Table 13. (continued).

6 hrs. old eggs

\begin{tabular}{|c|c|c|c|c|c|c|c|c|c|c|}
\hline \multirow{2}{*}{$\begin{array}{l}\text { Location } \\
\text { (depth) }\end{array}$} & \multirow{2}{*}{\begin{tabular}{|c|} 
Fertiliz. \\
$\begin{array}{c}\text { membrane } \\
\text { formation }\end{array}$ \\
\end{tabular}} & \multicolumn{3}{|c|}{ First cleavage $(120 \mathrm{~min})$} & \multicolumn{3}{|c|}{ Gastrulation (30 hrs.) } & \multicolumn{2}{|c|}{ Other notes } & \multirow{2}{*}{$\begin{array}{l}\text { Degree of } \\
\text { inhibitory } \\
\text { effect II }\end{array}$} \\
\hline & & 1 cell & $\begin{array}{c}2 \text { cell } \\
\text { (normal) }\end{array}$ & $\begin{array}{c}\text { multi-cell } \\
\text { (polyspermy) }\end{array}$ & $\begin{array}{l}\text { permanent } \\
\text { blastula }\end{array}$ & $\begin{array}{l}\text { gastrula } \\
\text { (normal) }\end{array}$ & exogastrula & $\begin{array}{c}\text { abnormal } \\
\text { develop. }\end{array}$ & $\mathrm{COD}$ & \\
\hline \multirow{3}{*}{$\begin{array}{l}\text { Running } \\
\text { sea water of } \\
\text { Laboratory }\end{array}$} & $92.5 \%$ & $8.5 \%$ & $91.5 \%$ & $0 \%$ & $1.0 \%$ & $99.0 \%$ & $0 \%$ & & $\mathrm{ppm}$ & \multirow{3}{*}{0} \\
\hline & 94.0 & 7. 0 & 92.0 & 1.0 & 0.5 & 99.5 & 0 & & & \\
\hline & 94.5 & 6.5 & 93.0 & 0.5 & 0.5 & 99.5 & 0 & & & \\
\hline \multirow{3}{*}{$\begin{array}{l}\text { Water from open sea } \\
\text { side of Hatakejima } \\
\text { Surface }\end{array}$} & 94.0 & 9.0 & 91.0 & 0 & 0.5 & 99.5 & 0 & & & \multirow{3}{*}{0} \\
\hline & 96.0 & 7.0 & 92.5 & 0.5 & 0.5 & 99.5 & 0 & & & \\
\hline & 97.5 & 5.0 & 95.0 & 0 & 0 & 100 & 0 & & & \\
\hline \multirow{3}{*}{ Bottom (25) } & 90.5 & 10.5 & 89.5 & 0 & 1.0 & 99.0 & 0 & & & \multirow{3}{*}{1} \\
\hline & 93.0 & 9.5 & 90.5 & 0 & 0.5 & 99.5 & 0 & & & \\
\hline & 94.5 & 9.0 & 91.0 & 0 & 0.5 & 99.5 & 0 & & & \\
\hline \multirow{3}{*}{$\begin{array}{l}\text { Water from land } \\
\text { side of Hatakejima } \\
\text { Surface }\end{array}$} & 85.5 & 17.5 & 82.5 & 0 & 2.0 & 98.0 & 0 & & & \multirow{3}{*}{1} \\
\hline & 90.0 & 11.5 & 87.5 & 1.0 & 2.5 & 97.5 & 0 & & & \\
\hline & 91.5 & 11.0 & 88.5 & 0.5 & 1.5 & 98.5 & 0 & & & \\
\hline \multirow{3}{*}{ Bottom (27) } & 84.5 & 17.5 & 82.5 & 0 & 3.5 & 96.5 & 0 & & 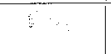 & \multirow{3}{*}{1} \\
\hline & 87.0 & 14.5 & 85.0 & 0.5 & 3.5 & 96.5 & 0 & & & \\
\hline & 89.0 & 13.5 & 86.5 & 0 & 2.5 & 97.5 & 0 & & & \\
\hline \multirow{3}{*}{$\begin{array}{l}\text { Sea water from } \\
\text { Tsunashirazu cove } \\
\text { Surface }\end{array}$} & 81.0 & 21.5 & 78.5 & 0 & 4.5 & 95.5 & 0 & & $\therefore$ & \multirow{3}{*}{2} \\
\hline & 84.0 & 18.5 & 80.5 & 1.0 & 4.0 & 96.0 & 0 & & & \\
\hline & 85.0 & 18.5 & 81.5 & 0 & 3.0 & 97.0 & 0 & & & \\
\hline \multirow{3}{*}{ Bottom (5) } & 83,5 & 19.5 & 80.5 & 0 & 4.0 & 96.0 & 0 & $\because \because$ & $\therefore$ & \multirow{3}{*}{2} \\
\hline & 87.0 & 15.0 & 84.0 & 1.0 & 3.5 & 96.5 & 0 & & & \\
\hline & 89.5 & 14.0 & 85.5 & 0.5 & 2.0 & 98.0 & 0 & & & \\
\hline
\end{tabular}


Table 14. Results of the July 3 experiment with eggs of Anthocidaris crassispina.

Wind ; 0 . Test water temperature ; $26^{\circ} \mathrm{C}$.

0 hr. old eggs

\begin{tabular}{|c|c|c|c|c|c|c|c|c|c|c|}
\hline \multirow{2}{*}{$\begin{array}{l}\text { Location } \\
\text { (depth) }\end{array}$} & \multirow{2}{*}{$\begin{array}{c}\text { Fertiliz. } \\
\text { membrane } \\
\text { formation }\end{array}$} & \multicolumn{3}{|c|}{ First cleavage $(60 \mathrm{~min})}$. & \multicolumn{3}{|c|}{ Gastrulation (17 hrs.) } & \multicolumn{2}{|c|}{ Other notes } & \multirow{2}{*}{$\begin{array}{l}\text { Degree of } \\
\text { inhibitory } \\
\text { effect I }\end{array}$} \\
\hline & & 1 cell & $\begin{array}{c}2 \text { cell } \\
(\text { normal) }\end{array}$ & $\begin{array}{c}\text { multi-cell } \\
\text { (polyspermy) }\end{array}$ & $\begin{array}{c}\text { permanent } \\
\text { blastula }\end{array}$ & $\begin{array}{c}\text { gastrula } \\
\text { (normal) }\end{array}$ & exogastrula & $\begin{array}{l}\text { abnormal } \\
\text { develop. }\end{array}$ & COD & \\
\hline \multirow{3}{*}{$\begin{array}{l}\text { Running } \\
\text { sea water of } \\
\text { Laboratory }\end{array}$} & $96.5 \%$ & $5.0 \%$ & $95.0 \%$ & $0 \%$ & $1.0 \%$ & $99.0 \%$ & $0 \%$ & & \multirow{3}{*}{$\begin{array}{l}\text { ppm } \\
0.95\end{array}$} & \multirow{3}{*}{1} \\
\hline & 97.0 & 5.5 & 94.5 & 0 & 0.5 & 99.5 & 0 & & & \\
\hline & 97.5 & 5.0 & 95.0 & 0 & 0.5 & 99.5 & 0 & & & \\
\hline \multirow{3}{*}{$\begin{array}{l}\text { Water from open sea } \\
\text { side of Hatakejima } \\
\text { Surface }\end{array}$} & 95.5 & 7.0 & 93.0 & 0 & 1.5 & 98.5 & 0 & & \multirow{3}{*}{1.33} & \multirow{3}{*}{1} \\
\hline & 97.5 & 4.5 & 95.5 & 0 & 1.5 & 98.5 & 0 & & & \\
\hline & 98.0 & 3.5 & 96.5 & 0 & 1.0 & 99.0 & 0 & & & \\
\hline \multirow{3}{*}{ Bottom (25) } & 96.0 & 6.5 & 93.5 & 0 & 1.0 & 99.0 & 0 & & \multirow{3}{*}{2.53} & \multirow{3}{*}{1} \\
\hline & 96.5 & 4.5 & 95.5 & 0 & 1.5 & 98.5 & 0 & & & \\
\hline & 96.0 & 4.5 & 95.5 & 0 & 1.0 & 99.0 & 0 & & & \\
\hline \multirow{3}{*}{$\begin{array}{l}\text { Water from land } \\
\text { side of Hatakejima } \\
\text { Surface }\end{array}$} & 93.5 & 17.5 & 82.5 & 0 & 2.0 & 98.0 & 0 & & \multirow{3}{*}{0.71} & \multirow{3}{*}{1} \\
\hline & 92.5 & 18.5 & 81.5 & 0 & 1.5 & 98.5 & 0 & & & \\
\hline & 93.5 & 18.0 & 82.0 & 0 & 1.5 & 98.5 & 0 & & & \\
\hline \multirow{3}{*}{ Bottom (27) } & 93.0 & 19.5 & 80.5 & 0 & 2.5 & 97.5 & 0 & & \multirow{3}{*}{2.02} & \multirow{3}{*}{1} \\
\hline & 93.5 & 17.5 & 82.5 & 0 & 2.0 & 98.0 & 0 & & & \\
\hline & 93.5 & 18.0 & 82.0 & 0 & 2.0 & 98.0 & 0 & & & \\
\hline \multirow{3}{*}{$\begin{array}{l}\text { Sea water from } \\
\text { Tsunashirazu cove } \\
\text { Surface }\end{array}$} & 89.5 & 22.5 & 77.5 & 0 & 3.0 & 97.0 & 0 & & \multirow{3}{*}{2,64} & \multirow{3}{*}{2} \\
\hline & 88.5 & 24.0 & 76.0 & 0 & 3.0 & 97.0 & 0 & & & \\
\hline & 89.0 & 23.0 & 77.0 & 0 & 2.5 & 97.5 & 0 & & & \\
\hline \multirow{3}{*}{ Bottom (5) } & 90.5 & 22.5 & 77.5 & 0 & 3.5 & 96,5 & 0 & & \multirow{3}{*}{2.42} & \multirow{3}{*}{2} \\
\hline & 91.0 & 20.5 & 79.5 & 0 & 3.0 & 97.0 & 0 & & & \\
\hline & 89.5 & 23.5 & 76.5 & 0 & 4.0 & 96.0 & 0 & & & \\
\hline
\end{tabular}


Table 14. (continued).

\begin{tabular}{|c|c|c|c|c|c|c|c|c|c|c|}
\hline \multirow{2}{*}{$\begin{array}{l}\text { Location } \\
\text { (depth) }\end{array}$} & \multirow{2}{*}{\begin{tabular}{|c|} 
Fertiliz. \\
$\begin{array}{c}\text { membrane } \\
\text { formation }\end{array}$
\end{tabular}} & \multicolumn{3}{|c|}{ First cleavage $(60 \mathrm{~min})}$. & \multicolumn{3}{|c|}{ Gastrulation (17 hrs.) } & \multicolumn{2}{|c|}{ Other notes } & \multirow{2}{*}{$\begin{array}{l}\text { Degree of } \\
\text { inhibitory } \\
\text { effect II }\end{array}$} \\
\hline & & 1 cell & $\begin{array}{c}2 \text { cell } \\
\text { (normal) }\end{array}$ & $\mid \begin{array}{c}\text { multi-cell } \\
\text { (polyspermy) }\end{array}$ & $\mid \begin{array}{c}\text { permanent } \\
\text { blastula }\end{array}$ & $\begin{array}{c}\text { gastrula } \\
\text { (normal) }\end{array}$ & exogastrula & $\begin{array}{l}\text { abnormal } \\
\text { develop. }\end{array}$ & COD & \\
\hline \multirow{3}{*}{$\begin{array}{l}\text { Running } \quad(\mathrm{m}) \\
\text { sea water of } \\
\text { Laboratory }\end{array}$} & $90.5 \%$ & $10.0 \%$ & $90.0 \%$ & $0 \%$ & $1.0 \%$ & $99.0 \%$ & $0 \%$ & & ppm & \\
\hline & 89.5 & 11.5 & 88.5 & 0 & 1.0 & 99.0 & 0 & & & 1 \\
\hline & 89.5 & 10.5 & 89.5 & 0 & 2.0 & 98.0 & 0 & & & \\
\hline \multirow{3}{*}{$\begin{array}{l}\text { Water from open sea } \\
\text { side of Hatakejima } \\
\text { Surface }\end{array}$} & 91.5 & 9.5 & 90.5 & 0 & 1.5 & 98.5 & 0 & & & \\
\hline & 90.5 & 10.0 & 90.0 & 0 & 2.0 & 98.0 & 0 & & & 1 \\
\hline & 89.5 & 13.0 & 87.0 & 0 & 2.5 & 97.5 & 0 & & & \\
\hline \multirow{3}{*}{ Bottom (25) } & 92.0 & 9.0 & 91.0 & 0 & 1.0 & 99.0 & 0 & & & \\
\hline & 91.0 & 10.0 & 90.0 & 0 & 1.5 & 98.5 & 0 & & & 1 \\
\hline & 88.5 & 12.5 & 87.5 & 0 & 2.5 & 97.5 & 0 & & & \\
\hline \multirow{3}{*}{$\begin{array}{l}\text { Water from land } \\
\text { side of Hatakejima } \\
\text { Surface }\end{array}$} & 87.5 & 24.0 & 76.0 & 0 & 2.5 & 97.5 & 0 & & & \\
\hline & 89.5 & 20.5 & 79.5 & 0 & 2.0 & 98.0 & 0 & . & & 2 \\
\hline & 84.5 & 25.0 & 75.0 & 0 & 3.5 & 96.5 & 0 & & & \\
\hline \multirow{3}{*}{ Bottom (27) } & 85.0 & 26,5 & 73.5 & 0 & 2.5 & 97.5 & 0 & & & \\
\hline & 85.5 & 22.0 & 78.0 & 0 & 2.5 & 97.5 & 0 & & & 2 \\
\hline & 83.5 & 25.5 & 74.5 & 0 & 3.0 & 97.0 & 0 & & & \\
\hline \multirow{3}{*}{$\begin{array}{l}\text { Sea water from } \\
\text { Tsunashirazu cove } \\
\text { Surface }\end{array}$} & 83.5 & 29.5 & 70.5 & 0 & 3.0 & 97.0 & 0 & & & \\
\hline & 84.5 & 32.0 & 68.0 & 0 & 3.5 & 96.5 & 0 & & & 3 \\
\hline & 82.5 & 31.0 & 69.0 & 0 & 4.5 & 95.5 & 0 & & & \\
\hline \multirow{3}{*}{ Bottom (5) } & 82.5 & 28,5 & 71.5 & 0 & 3.5 & 96.5 & 0 & & & \\
\hline & 81.5 & 31.5 & 68.5 & 0 & 4.0 & 96.0 & 0 & & & 3 \\
\hline & 80.0 & 29.0 & 71.0 & 0 & 4.0 & 96.0 & 0 & & & \\
\hline
\end{tabular}


Table 15. Results of the Aug. 30 experiment with eggs of Anthocidaris crassispina.

Wind; 0 . Test water temperature; $28^{\circ} \mathrm{C}$.

0. hr. old eggs

\begin{tabular}{|c|c|c|c|c|c|c|c|c|c|c|}
\hline \multirow{2}{*}{$\begin{array}{l}\text { Location } \\
\text { (depth) }\end{array}$} & \multirow{2}{*}{\begin{tabular}{|c|} 
Fertiliz. \\
membrane \\
formation
\end{tabular}} & \multicolumn{3}{|c|}{ First cleavage $(50 \mathrm{~min})}$. & \multicolumn{3}{|c|}{ Gastrulation (12 hrs.) } & \multicolumn{2}{|c|}{ Other notes } & \multirow{2}{*}{$\begin{array}{l}\text { Degree of } \\
\text { inhibitory } \\
\text { effect I }\end{array}$} \\
\hline & & 1 cell & $\begin{array}{c}2 \text { cell } \\
\text { (normal) }\end{array}$ & $\begin{array}{c}\text { multi-cell } \\
\text { (polyspermy) }\end{array}$ & $\begin{array}{c}\text { permanent } \\
\text { blastula }\end{array}$ & $\begin{array}{c}\text { gastrula } \\
\text { (normal) }\end{array}$ & exogastrula & $\begin{array}{l}\text { abnormal } \\
\text { develop. }\end{array}$ & $\mathrm{COD}$ & \\
\hline $\begin{array}{l}\text { Running } \\
\text { sea water of } \\
\text { Laboratory }\end{array}$ & $\begin{array}{l}97.5 \% \\
96.5 \\
97.0\end{array}$ & $\begin{array}{l}3.5 \% \\
4.0 \\
3.0\end{array}$ & $\begin{array}{l}96.5 \% \\
96.0 \\
97.0\end{array}$ & \begin{tabular}{ll|}
0 & $\%$ \\
0 & \\
0 &
\end{tabular} & $\begin{array}{l}1.0 \% \\
0.5 \\
0.5\end{array}$ & $\begin{array}{l}99.0 \% \\
99.5 \\
99.5\end{array}$ & $\begin{array}{ll}0 & \% \\
0 & \\
0 & \end{array}$ & & $\begin{array}{l}\text { ppm } \\
0.87\end{array}$ & 1 \\
\hline $\begin{array}{l}\text { Water from open sea } \\
\text { side of Hatakejima } \\
\text { Surface }\end{array}$ & $\begin{array}{l}98.0 \\
97.5 \\
96.5\end{array}$ & $\begin{array}{l}2.5 \\
3.0 \\
4.0\end{array}$ & $\begin{array}{l}97.5 \\
97.0 \\
96.0\end{array}$ & $\begin{array}{l}0 \\
0 \\
0\end{array}$ & $\begin{array}{l}1.0 \\
1.0 \\
0.5\end{array}$ & $\begin{array}{l}99.0 \\
99.0 \\
99.5\end{array}$ & $\begin{array}{l}0 \\
0 \\
0\end{array}$ & & 1.22 & 1 \\
\hline Bottom (25) & $\begin{array}{l}98.0 \\
97.0 \\
96.5\end{array}$ & $\begin{array}{l}2.5 \\
3.0 \\
4.5\end{array}$ & $\begin{array}{l}97.5 \\
97.0 \\
95.5\end{array}$ & $\begin{array}{l}0 \\
0 \\
0\end{array}$ & $\begin{array}{l}1.0 \\
2.0 \\
1.5\end{array}$ & $\begin{array}{l}99.0 \\
98.0 \\
98.5\end{array}$ & $\begin{array}{l}0 \\
0 \\
0\end{array}$ & & 1.45 & 1 \\
\hline $\begin{array}{l}\text { Water from land } \\
\text { side of Hatakejima } \\
\text { Surface }\end{array}$ & $\begin{array}{l}96.0 \\
96.5 \\
95.5\end{array}$ & $\begin{array}{l}13.5 \\
15.5 \\
15.5 \\
\end{array}$ & $\begin{array}{l}86.5 \\
84.5 \\
84.5\end{array}$ & $\begin{array}{l}0 \\
0 \\
0\end{array}$ & $\begin{array}{l}1.5 \\
2.0 \\
2.0\end{array}$ & $\begin{array}{l}98.5 \\
98.0 \\
98.0\end{array}$ & $\begin{array}{l}0 \\
0 \\
0\end{array}$ & & 1.80 & 1 \\
\hline Bottom (27) & $\begin{array}{l}94.5 \\
95.0 \\
94.0\end{array}$ & $\begin{array}{l}14.5 \\
17.0 \\
18.5\end{array}$ & $\begin{array}{l}85.5 \\
83.0 \\
81.5\end{array}$ & $\begin{array}{l}0 \\
0 \\
0\end{array}$ & $\begin{array}{l}2.0 \\
2.5 \\
2.5\end{array}$ & $\begin{array}{l}98.0 \\
97.5 \\
97.5\end{array}$ & $\begin{array}{l}0 \\
0 \\
0\end{array}$ & & 2.67 & 1 \\
\hline $\begin{array}{l}\text { Sea water from } \\
\text { Tsunashirazu cove } \\
\text { Surface }\end{array}$ & $\begin{array}{l}84.0 \\
88.5 \\
86.5\end{array}$ & $\begin{array}{l}20.5 \\
19.5 \\
21.5\end{array}$ & $\begin{array}{l}79.5 \\
80.5 \\
78.5\end{array}$ & $\begin{array}{l}0 \\
0 \\
0\end{array}$ & $\begin{array}{l}3.0 \\
3.0 \\
3.5\end{array}$ & $\begin{array}{l}97.0 \\
97.0 \\
96.5\end{array}$ & $\begin{array}{l}0 \\
0 \\
0\end{array}$ & & 1.24 & 2 \\
\hline Bottom (5) & $\begin{array}{l}85.5 \\
87.0 \\
87.0\end{array}$ & $\begin{array}{l}21.0 \\
21.5 \\
21.0\end{array}$ & $\begin{array}{l}79.0 \\
78.5 \\
79.0\end{array}$ & $\begin{array}{l}0 \\
0 \\
0\end{array}$ & $\begin{array}{l}3.5 \\
4.0 \\
4.5\end{array}$ & $\begin{array}{l}96.5 \\
96.0 \\
95.5\end{array}$ & $\begin{array}{l}0 \\
0 \\
0\end{array}$ & & 3.04 & 2 \\
\hline
\end{tabular}


Table 15. (continued).

\begin{tabular}{|c|c|c|c|c|c|c|c|c|c|c|}
\hline \multirow{2}{*}{$\begin{array}{l}\text { Location } \\
\text { (depth) }\end{array}$} & \multirow{2}{*}{$\begin{array}{l}\text { Fertiliz. } \\
\text { membrane } \\
\text { formation }\end{array}$} & \multicolumn{3}{|c|}{ First cleavage (50 min.) } & \multicolumn{3}{|c|}{ Gastrulation (12 hrs.) } & \multicolumn{2}{|c|}{ Other notes } & \multirow{2}{*}{$\begin{array}{l}\text { Degree of } \\
\text { inhibitory } \\
\text { effect II }\end{array}$} \\
\hline & & 1 cell & $\begin{array}{c}2 \text { cell } \\
(\text { normal) }\end{array}$ & $\begin{array}{c}\text { multi-cell } \\
\text { (polyspermy) }\end{array}$ & $\begin{array}{c}\text { permanent } \\
\text { blastula }\end{array}$ & $\begin{array}{c}\text { gastrula } \\
\text { (normal) }\end{array}$ & exogastrula & $\begin{array}{l}\text { abnormal } \\
\text { develop. }\end{array}$ & COD & \\
\hline \multirow{3}{*}{$\begin{array}{l}\text { Running } \\
\text { sea water of } \\
\text { Laboratory }\end{array}$} & $93.5 \%$ & $7.5 \%$ & $92.5 \%$ & $0 \%$ & $1.0 \%$ & $99.0 \%$ & $0 \%$ & & ppm & \\
\hline & 94.5 & 7.0 & 93.0 & 0 & 1.0 & 99.0 & 0 & & & 0 \\
\hline & 92.0 & 9.0 & 91.0 & 0 & 1.5 & 98.5 & 0 & & & \\
\hline \multirow{3}{*}{$\begin{array}{l}\text { Water from open sea } \\
\text { side of Hatakejima } \\
\text { Surface }\end{array}$} & 92.5 & 7.5 & 92.0 & 0.5 & 1.5 & 98.5 & 0 & & & \\
\hline & 93.0 & 8.0 & 91.5 & 0.5 & 1.0 & 99.0 & 0 & & & 0 \\
\hline & 91.5 & 9.5 & 90.5 & 0 & 1.5 & 98.5 & 0 & & & \\
\hline \multirow{3}{*}{ Bottom (25) } & 91.0 & 9.5 & 90.0 & 0.5 & 1.5 & 98.5 & 0 & & & \\
\hline & 90.0 & 11.0 & 89.0 & 0 & 1.5 & 98.5 & 0 & & & 1 \\
\hline & 90.0 & 11.0 & 88.0 & 1.0 & 2.0 & 98.0 & 0 & & & \\
\hline \multirow{3}{*}{$\begin{array}{l}\text { Water from land } \\
\text { side of Hatakejima } \\
\text { Surface }\end{array}$} & 89.5 & 12.0 & 87.0 & 1.0 & 2.0 & 98.0 & 0 & & & \\
\hline & 87.0 & 13.0 & 85.5 & 1.5 & 2.5 & 97.5 & 0 & & & 2 \\
\hline & 86.5 & 19.5 & 79.5 & 1.0 & 2.5 & 97.5 & 0 & & & \\
\hline \multirow{3}{*}{ Bottom (27) } & 86.5 & 14.5 & 84.0 & 1.5 & 3.5 & 96.5 & 0 & & & \\
\hline & 84.0 & 17. 0 & 81.0 & 2.0 & 3.0 & 97.0 & 0 & $\cdot$ & & 2 \\
\hline & 82.0 & 18.5 & 79.5 & 2.0 & 3.5 & 96.5 & 0 & & & \\
\hline Sea water from & 82.0 & 15: 5 & 73.5 & 1.0 & 4.5 & 95.5 & 0 & & & \\
\hline Tsunashirazu cove & 80.5 & 16.5 & 71.0 & 2.5 & 4.0 & 96.0 & 0 & & & 3 \\
\hline Surface & 76.5 & 28.5 & 69.5 & 2.0 & 4.0 & 96.0 & 0 & & & \\
\hline \multirow{3}{*}{ Bottom (5) } & 82.5 & 26.0 & 72.5 & 1.5 & 4.5 & 95.5 & 0 & & & \\
\hline & 75.0 & 26.0 & 71.5 & 2.5 & 5.0 & 95.0 & 0 & & & 3 \\
\hline & 72.5 & 28.5 & 69.0 & 2.5 & 5.0 & 95.0 & 0 & & & \\
\hline
\end{tabular}


Table 16. Results of the Sept. 14 experiment with eggs of Anthocidaris crassispina.

Wind NW 1. Test water temperature; $25^{\circ} \mathrm{C}$.

0 hr. old eggs

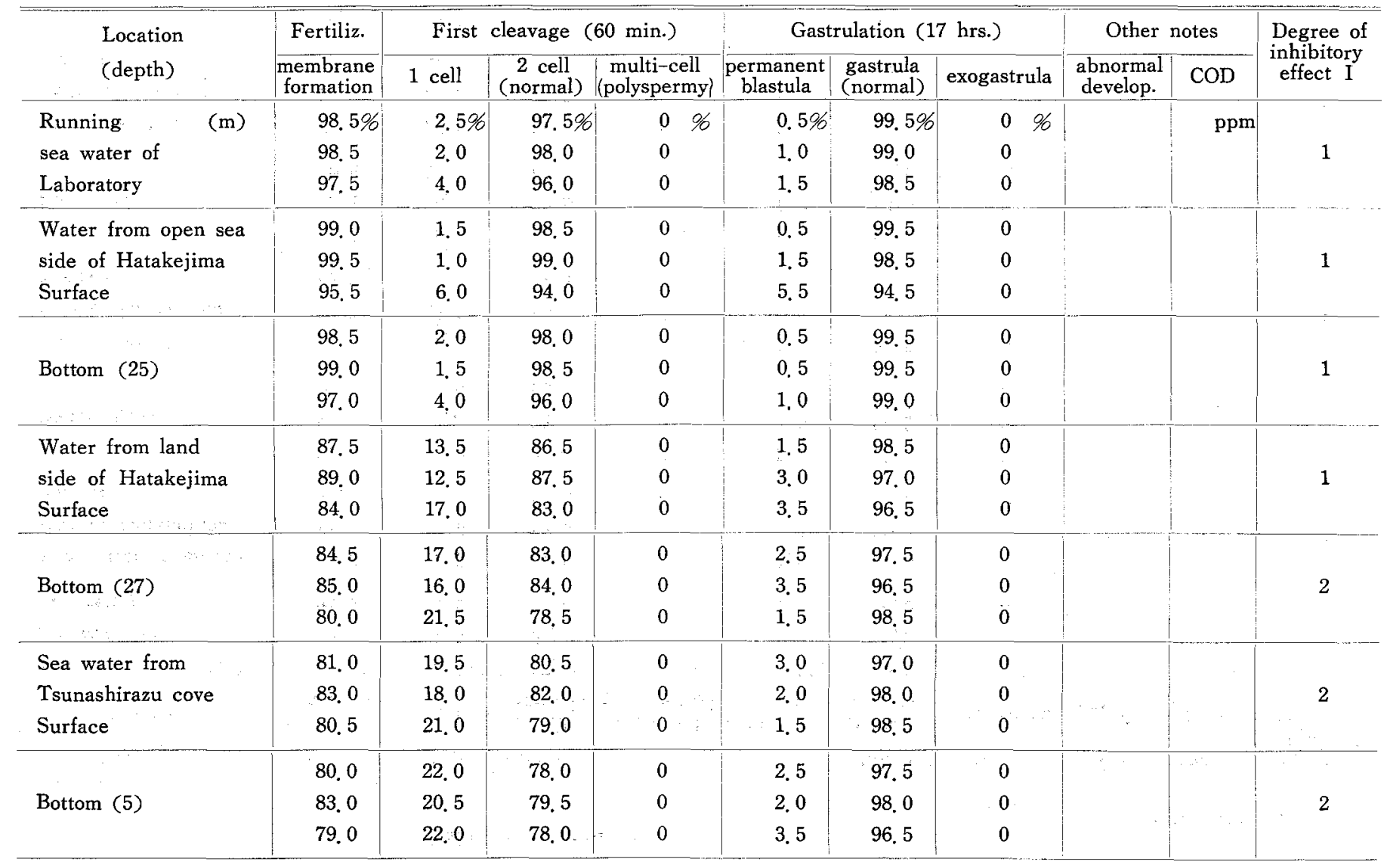


Table 16. (continued).

3 hrs. old eggs

\begin{tabular}{|c|c|c|c|c|c|c|c|c|c|c|}
\hline \multirow{2}{*}{$\begin{array}{l}\text { Location } \\
\text { (depth) }\end{array}$} & \multirow{2}{*}{\begin{tabular}{|c|} 
Fertiliz. \\
membrane \\
formation
\end{tabular}} & \multicolumn{3}{|c|}{ First cleavage $(60 \mathrm{~min})}$. & \multicolumn{3}{|c|}{ Gastrulation (17 hrs.) } & \multicolumn{2}{|c|}{ Other notes } & \multirow{2}{*}{$\begin{array}{l}\text { Degree of } \\
\text { inhibitory } \\
\text { effect II }\end{array}$} \\
\hline & & 1 cell & $\begin{array}{c}2 \text { cell } \\
\text { (normal) }\end{array}$ & $\begin{array}{c}\text { multi-cell } \\
\text { (polyspermy) }\end{array}$ & $\begin{array}{c}\text { permanent } \\
\text { blastula }\end{array}$ & $\begin{array}{l}\text { gastrula } \\
\text { (normal) }\end{array}$ & exogastrula & $\begin{array}{c}\text { abnormal } \\
\text { develop. }\end{array}$ & COD & \\
\hline \multirow{3}{*}{$\begin{array}{l}\text { Running } \\
\text { sea water of } \\
\text { Laboratory }\end{array}$} & $97.5 \%$ & $3.0 \%$ & $97.0 \%$ & $0 \not 6$ & $1.0 \%$ & $99.0 \%$ & $0 \%$ & & ppm & \multirow{3}{*}{0} \\
\hline & 98.5 & 2.5 & 97.5 & 0 & 0.5 & 99.5 & 0 & & & \\
\hline & 96.5 & 4.0 & 96.0 & 0 & 1.5 & 98.5 & 0 & & & \\
\hline \multirow{3}{*}{$\begin{array}{l}\text { Water from open sea } \\
\text { side of Hatakejima } \\
\text { Surface }\end{array}$} & 98.0 & 2.5 & 97.5 & 0 & 1.0 & 99.0 & 0 & & & \multirow{3}{*}{0} \\
\hline & 98.5 & 2.0 & 98.0 & 0 & 0.5 & 99.5 & 0 & & & \\
\hline & 97.0 & 3.0 & 97.0 & 0 & 4.0 & 96.0 & 0 & & & \\
\hline \multirow{3}{*}{ Bottom (25) } & 97.5 & 3.0 & 97.0 & 0 & 2.0 & 98.0 & 0 & & & \multirow{3}{*}{0} \\
\hline & 99.0 & 1.5 & 98.5 & 0 & 1.5 & 98.5 & 0 & & & \\
\hline & 97.0 & 3.5 & 96.5 & 0 & 3.0 & 97.0 & 0 & & & \\
\hline \multirow{3}{*}{$\begin{array}{l}\text { Water from land } \\
\text { side of Hatakejima } \\
\text { Surface }\end{array}$} & 85.5 & 17.0 & 83.0 & 0 & 1.5 & 98.5 & 0 & & & \multirow{3}{*}{1} \\
\hline & 87.5 & 13.5 & 86.5 & 0 & 2.0 & 98.0 & 0 & & & \\
\hline & 83.0 & 17.5 & 82.5 & 0 & 2.5 & 97.5 & 0 & & & \\
\hline \multirow{3}{*}{ Bottom (27) } & 73.5 & 30.5 & 69.5 & 0 & 6.5 & 93.5 & 0 & & & \multirow{3}{*}{3} \\
\hline & 72.5 & 29.5 & 70.5 & 0 & 6.0 & 94.0 & 0 & & & \\
\hline & 70.5 & 33.0 & 67.0 & 0 & 7. 0 & 93.0 & 0 & & & \\
\hline \multirow{3}{*}{$\begin{array}{l}\text { Sea water from } \\
\text { Tsunashirazu cove } \\
\text { Surface }\end{array}$} & 77.0 & 26.0 & 74.0 & 0 & 5.5 & 94.5 & 0 & & & \multirow{3}{*}{2} \\
\hline & 75.0 & 25.5 & 74.5 & 0 & 6.5 & 93.5 & 0 & & & \\
\hline & 73.5 & 27.0 & 73.0 & 0 & 7.0 & 93.0 & 0 & & & \\
\hline \multirow{3}{*}{ Bottom (5) } & 75.5 & 31.0 & 69.0 & 0 & 9.5 & 90.5 & 0 & & & \multirow{3}{*}{3} \\
\hline & 74.5 & 28.0 & 72.0 & 0 & 6.5 & 93.5 & 0 & & & \\
\hline & 69.0 & 33.0 & 67.0 & 0 & 8.0 & 92.0 & 0 & & & \\
\hline
\end{tabular}


Table 17. Results of the Nov. 27 experiment with eggs of Pseudocentrotus depressus.

Wind; 0 . Test water temperature; $13^{\circ} \mathrm{C}$.

0 hr. old eggs

\begin{tabular}{|c|c|c|c|c|c|c|c|c|c|c|}
\hline \multirow{2}{*}{$\begin{array}{l}\text { Location } \\
\text { (depth) }\end{array}$} & \multirow{2}{*}{$\left|\frac{\text { Fertiliz. }}{\text { membrane }}\right|$} & \multicolumn{3}{|c|}{ First cleavage $(150 \mathrm{~min})}$. & \multicolumn{3}{|c|}{ Gastrulation ( $35 \mathrm{hrs}$ ) } & \multicolumn{2}{|c|}{ Other notes } & \multirow{2}{*}{$\begin{array}{l}\text { Degree of } \\
\text { inhibitory } \\
\text { effect }\end{array}$} \\
\hline & & 1 cell & $\begin{array}{c}2 \text { cell } \\
\text { (normal) }\end{array}$ & $\begin{array}{c}\text { multi-cell } \\
\text { (polyspermy) }\end{array}$ & $\begin{array}{c}\text { permanent } \\
\text { blastula }\end{array}$ & $\begin{array}{c}\text { gastula } \\
\text { (normal) }\end{array}$ & exogastrula & $\begin{array}{l}\text { abnormal } \\
\text { develop. }\end{array}$ & COD & \\
\hline \multirow{2}{*}{$\begin{array}{l}\text { Running } \\
\text { sea water of } \\
\text { Laboratory }\end{array}$} & $98,5 \%$ & $2.5 \%$ & $97.5 \%$ & $0 \%$ & $1.0 \%$ & $99.0 \%$ & $0 \%$ & & ppm & 1 \\
\hline & 99.5 & 1.0 & 99.0 & 0 & 0.5 & 99.5 & 0 & & & \\
\hline \multirow{2}{*}{$\begin{array}{l}\text { Water from open sea } \\
\text { side of Hatakejima } \\
\text { Surface }\end{array}$} & 98.5 & 2.5 & 97.5 & 0 & 1.0 & 99.0 & 0 & & & \multirow{2}{*}{1} \\
\hline & 98.0 & 3.0 & 97.0 & 0 & 0.5 & 99.5 & 0 & & & \\
\hline \multirow{2}{*}{ Bottom (25) } & 98.0 & 3.0 & 97.0 & 0 & 1.5 & 99.5 & 0 & & & \multirow{2}{*}{1} \\
\hline & 97.0 & 3.5 & 96.5 & 0 & 1.0 & 99.0 & 0 & & & \\
\hline \multirow{2}{*}{$\begin{array}{l}\text { Water from land } \\
\text { side of Hatakejima } \\
\text { Surface }\end{array}$} & 97: 0 & 4.5 & 95.5 & 0 & 1.5 & 98.5 & 0 & & & \multirow{2}{*}{1} \\
\hline & 97.0 & 4.0 & 96.0 & 0 & 2.0 & 98.0 & 0 & & & \\
\hline \multirow{2}{*}{ Bottom (27) } & 93.0 & 8.5 & 91.5 & 0 & 2.5 & 97.5 & 0 & & & \multirow{2}{*}{1} \\
\hline & 91.5 & 10.0 & 90.0 & 0 & 2.0 & 98.0 & 0 & & & \\
\hline \multirow{2}{*}{$\begin{array}{l}\text { Sea water from } \\
\text { Tsunashirazu cove } \\
\text { Surface }\end{array}$} & 89.5 & 13.0 & 87.0 & 0 & 3.0 & 97.0 & 0 & & & \multirow{2}{*}{1} \\
\hline & 87.5 & 14,0 & 86.0 & 0 & 2.0 & 98.0 & 0 & & & \\
\hline \multirow{2}{*}{ Bottom (5) } & 84.0 & 18.5 & 81.5 & 0 & 3.5 & 96.5 & 0 & & & \multirow{2}{*}{2} \\
\hline & 85.0 & 16.5 & 83.5 & 0 & 3.0 & 97.0 & 0 & & & \\
\hline
\end{tabular}


Table 17. (continued).

10 hrs. old eggs

\begin{tabular}{|c|c|c|c|c|c|c|c|c|c|c|}
\hline \multirow{2}{*}{$\begin{array}{l}\text { Location } \\
\text { (depth) }\end{array}$} & \multirow{2}{*}{$\begin{array}{c}\text { Fertiliz. } \\
\begin{array}{c}\text { membrane } \\
\text { formation }\end{array} \\
\end{array}$} & \multicolumn{3}{|c|}{ First cleavage $(150 \mathrm{~min})}$. & \multicolumn{3}{|c|}{ Gastrulation ( $35 \mathrm{hrs}$.) } & \multicolumn{2}{|c|}{ Other notes } & \multirow{2}{*}{$\begin{array}{l}\text { Degree of } \\
\text { inhibitory } \\
\text { effect II }\end{array}$} \\
\hline & & 1 cell & $\begin{array}{c}2 \text { cell } \\
(\text { normal) }\end{array}$ & $\begin{array}{c}\text { multi-cell } \\
\text { (polyspermy) }\end{array}$ & $\begin{array}{c}\text { permanent } \\
\text { blastula }\end{array}$ & $\begin{array}{c}\text { gastrula } \\
\text { (normal) }\end{array}$ & exogastrula & $\begin{array}{l}\text { abnormal } \\
\text { develop. }\end{array}$ & COD & \\
\hline $\begin{array}{l}\text { Running } \\
\text { sea water of } \\
\text { Laboratory }\end{array}$ & $\begin{array}{l}93.5 \% \\
94.5\end{array}$ & $\begin{array}{l}9.0 \% \\
7.5\end{array}$ & $\begin{array}{l}91.0 \% \\
92.5\end{array}$ & $\begin{array}{l}0 \% \\
0\end{array}$ & $\begin{array}{l}0.5 \% \\
1.0\end{array}$ & $\begin{array}{l}99.5 \% \\
99.0\end{array}$ & $\begin{array}{l}0 \% \\
0\end{array}$ & & $\mathrm{ppm}$ & 0 \\
\hline $\begin{array}{l}\text { Water from open sea } \\
\text { side of Hatakejima } \\
\text { Surface }\end{array}$ & $\begin{array}{l}94.0 \\
94.5\end{array}$ & $\begin{array}{l}7.0 \\
6.0\end{array}$ & $\begin{array}{l}93.0 \\
94.0\end{array}$ & $\begin{array}{l}0 \\
0\end{array}$ & $\begin{array}{l}2.0 \\
1.0\end{array}$ & $\begin{array}{l}98.0 \\
99.0\end{array}$ & $\begin{array}{l}0 \\
0\end{array}$ & & & 0 \\
\hline Bottom (25) & $\begin{array}{l}92.5 \\
93.0\end{array}$ & $\begin{array}{l}9.5 \\
8.0\end{array}$ & $\begin{array}{l}90.5 \\
92.0\end{array}$ & $\begin{array}{l}0 \\
0\end{array}$ & $\begin{array}{l}1.5 \\
2.0\end{array}$ & $\begin{array}{l}98.5 \\
98.0\end{array}$ & $\begin{array}{l}0 \\
0\end{array}$ & & & 0 \\
\hline $\begin{array}{l}\text { Water from land } \\
\text { side of Hatakejima } \\
\text { Surface }\end{array}$ & $\begin{array}{l}90.5 \\
92.0\end{array}$ & $\begin{array}{l}14.0 \\
10,0\end{array}$ & $\begin{array}{l}86.0 \\
90.0\end{array}$ & $\begin{array}{l}0 \\
0\end{array}$ & $\begin{array}{l}1.5 \\
2.0\end{array}$ & $\begin{array}{l}98.5 \\
98.0\end{array}$ & $\begin{array}{l}0 \\
0\end{array}$ & & & 1 \\
\hline Bottom (27) & $\begin{array}{l}87.0 \\
84.5\end{array}$ & $\begin{array}{l}18.0 \\
19.5\end{array}$ & $\begin{array}{l}81.5 \\
80.0\end{array}$ & $\begin{array}{l}0.5 \\
0.5\end{array}$ & $\begin{array}{l}2.5 \\
3.0\end{array}$ & $\begin{array}{l}97.5 \\
97.0\end{array}$ & $\begin{array}{l}0 \\
0\end{array}$ & & & 2 \\
\hline $\begin{array}{l}\text { Sea water from } \\
\text { Tsunashirazu cove } \\
\text { Surface }\end{array}$ & $\begin{array}{l}90.0 \\
93.0\end{array}$ & $\begin{array}{r}16.5 \\
10.5\end{array}$ & $\begin{array}{l}83.5 \\
89.5\end{array}$ & $\begin{array}{l}0 \\
0\end{array}$ & $\begin{array}{l}3.5 \\
3.5\end{array}$ & $\begin{array}{l}96.5 \\
96.5\end{array}$ & $\begin{array}{l}0 \\
0\end{array}$ & & & 1 \\
\hline Bottom (5) & $\begin{array}{l}81.5 \\
80.5\end{array}$ & $\begin{array}{l}21.0 \\
21.0\end{array}$ & $\begin{array}{l}78.0 \\
78.5\end{array}$ & $\begin{array}{l}1.0 \\
0.5\end{array}$ & $\begin{array}{l}3.5 \\
4.5\end{array}$ & $\begin{array}{l}96.5 \\
95.5\end{array}$ & $\begin{array}{l}0 \\
0\end{array}$ & & & 2 \\
\hline
\end{tabular}

